OPEN ACCESS

Edited by:

Claudia Kuntner

Austrian Institute of Technology

(AIT), Austria

Reviewed by:

Violaine See,

University of Liverpool,

United Kingdom

Anne Herrmann,

University of Liverpool,

United Kingdom

*Correspondence:

Volker Rasche

volker.rasche@uni-ulm.de

Specialty section:

This article was submitted to

Medical Physics and Imaging,

a section of the journal

Frontiers in Physics

Received: 02 December 2019

Accepted: 15 April 2020

Published: 25 May 2020

Citation:

Winter G, Koch ABF, Löffler J,

Jelezko F, Lindén M, Li H, Abaei A,

Zuo Z, Beer AJ and Rasche V (2020)

In vivo PET/MRI Imaging of the

Chorioallantoic Membrane.

Front. Phys. 8:151

doi: 10.3389/fphy.2020.00151

\section{In vivo PET/MRI Imaging of the Chorioallantoic Membrane}

\author{
Gordon Winter ${ }^{1}$, Andrea B. F. Koch ${ }^{1}$, Jessica Löffler ${ }^{1,2}$, Fedor Jelezko ${ }^{3}$, Mika Lindén ${ }^{4}$, \\ Hao Li $^{2,5}$, Alireza Abaei ${ }^{2}$, Zhi Zuo ${ }^{2,6}$, Ambros J. Beer ${ }^{1}$ and Volker Rasche ${ }^{2,7 *}$ \\ ${ }^{1}$ Department of Nuclear Medicine, Ulm University Medical Center, Ulm, Germany, ${ }^{2}$ Core Facility Small Animal MRI, Medical \\ Faculty, Ulm University, Ulm, Germany, ${ }^{3}$ Institute for Quantum Optics, Ulm University, Ulm, Germany, ${ }^{4}$ Institute for Inorganic \\ Chemistry II, UIm University, UIm, Germany, ${ }^{5}$ Department of Cardiology, The Second Hospital of Shandong University, Jinan, \\ China, ${ }^{6}$ Department of Cardiology, Zhongda Hospital, Medical School of Southeast University, Nanjing, China, ${ }^{7}$ Department \\ of Internal Medicine 2, Ulm University Medical Center, Ulm, Germany
}

The Hen's Egg Test Chorioallantoic Membrane (HET-CAM) of fertilized chick eggs represents a unique model for biomedical research. With its steadily increasing use, non-invasive in ovo imaging for longitudinal direct quantification of the biodistribution of compounds or monitoring of surrogate markers has been introduced. The full range of imaging methods has been applied to the HET-CAM model. From the current perspective, Magnetic Resonance Imaging (MRI) and Positron Emission Tomography (PET) appear promising techniques, providing detailed anatomical and functional information (MRI) and excellent sensitivity (PET). Especially by combining both techniques, the required sensitivity and anatomical localization of the signal source renders feasible. In the following, a review of recent applications of MRI and PET for in ovo imaging with a special focus on techniques for imaging xenotransplanted tumors on the CAM will be provided.

Keywords: HET-CAM, MRI, PET, imaging, biodistribution, targeting

\section{INTRODUCTION}

The Hen's Egg Test Chorioallantoic-Membrane (HET-CAM) of fertilized chicken eggs represents a unique model for biomedical research. During the development, the mesodermal layers of the allantois and chorion form the chorioallantoic membrane (CAM). This structure forms a rich vascular network enabling to study tissue grafts, tumor growth, metastasis formation, wound healing, drug delivery, toxicologic analysis, angiogenic and anti-angiogenic molecules [1].

The HET-CAM represents a relatively simple, quick, and low-cost model that allows screening of a large number of pharmacological samples in a short time. It has been successfully used to study cancer progression and its pharmacological treatment [2-8], angiogenesis [9], pharmacokinetics [10], properties of novel nanomaterials [9, 11], or as a model system to study microsurgical instruments and techniques [12]. Especially for xenotransplantation tumor models, the HET-CAM offers various advantages in comparison to the murine models. Since the development of the lymphoid system starts in the late stage of incubation, the HET-CAM model represents a naturally immunodeficient host, enabling xenotransplantation of many kinds of tumors without species-specific limitations [11]. The blood vessel network of the CAM thereby provides an excellent environment for primary tumor formation and a basis for angiogenic blood vessel formation [12]. Human cell line derived [13] xenografts are considered an increasingly valuable tool in oncology potentially providing biologically models of many different cancer types. Where immunodeficient rodent models 
pose barriers to widespread application due to cost and efficiency constraints, the HET-CAM model renders as efficient model especially for initial testing of tumor progression [10, 1416], in many countries not requiring any approval for animal experiments, if sacrificed before hatching.

Due to its simplicity, the HET-CAM model appears as ideal platform for initial testing of pharmacological compounds and tissue properties, including biodistribution assessment or efficacy assessment of new compounds [1, 8, 13-19].

With the increasing use of the HET-CAM model and the need for longitudinal monitoring, non-invasive in ovo imaging of the chick embryo and especially the CAM has gained interest over recent years. Optical methods like optical coherence tomography (OCT) and Doppler techniques have successfully been applied for deriving functional and physiological properties of the embryo [20-38]. Three-dimensional microcomputed tomography ( $\mu \mathrm{CT})$ has been applied in ovo, especially in the field of bone volume and mineral density assessment [39-46]. With the recent advances in magnetic resonance tomography (MRI) its application to in ovo imaging has rendered feasible and many applications of the technique in the live embryo as well as after sacrification have been reported for different scientific fields, including embryonal development [47-54], ophthalmology [48-57], oncology [5863], metabolic assessment [54, 64], and initial testing of the biodistribution of new compounds [65-67]. Further, nuclear imaging methods have been translated to in ovo imaging, mainly for initial testing of new labeling strategies [19, 68-71].

Considering the capability of the HET-CAM model for monitoring the growth and progression of xenotransplanted tumors rises a huge potential for its use in the evaluation of the biodistribution of new compounds, especially in combination with specific targeting strategies. In this context the combination of the multi-contrast capabilities of MRI with the outstanding sensitivity of positron emission tomography (PET) appears promising. In the following a review of recent applications of MRI and PET for in ovo imaging with a special focus on techniques for imaging xenotransplanted tumors on the CAM will be provided.

\section{THE HET-CAM MODEL}

In preclinical research and drug development can-cer cell lines (CCL) are frequently used. However, in culture, CCLs often fail to retain morphology, cellular heterogeneity, and molecular profiles of the donor tissue $[72,73]$, and drug performance in xenografts may not perfectly reflect clinical efficacy [74]. The success of new drugs in oncology requires preclinical models that render the full heterogeneity and pathophysiology of patient tumors, and CCL or patient-derived xenografts (PDX) may mimic physiological drug effects $[75,76]$.

A broad range of applications for CCL and PDX have been reported using rodent models as host and their efficient use in prediction of response, development of biomarkers, and monitoring and identification of efficient treatment regimens has been proven [77]. Despite their frequent use, rodent models have practical and scientific limitations. In many applications, rodent models have shown a very limited success rate in engraftment. Successful engraftment often takes several months. Further high, often prohibitive costs and resources are required for keeping rodents in an appropriate facility under proper hygienic conditions. They are labor-intensive, time-consuming, and require ethical approval by the regulatory authorities.

The HET-CAM model represents a well-established alternative in vivo assay. It presents a highly vascularized extra-embryonic membrane, which is connected to the embryo through a continuous circulatory system. Even though $\mathrm{T}$ and $\mathrm{B}$ cells can be detected in the chick embryo immune system by embryo development day (EDD) 11 and 12, full immune competence is not developed until EDD 18 [16]. The HET-CAM is a low-cost model with the limita-tion of developing a nonspecific inflammatory response after EDD 15 [1]. Xenotransplantation and growth of cancer cell lines on the CAM is well-established (Figure 1) and has amongst others been applied for initial assessment of the efficacy of anticancer drugs [78]. Compared to the rodent models, tumor formation on the CAM is fast, with graft vascularization and thus interface to the chick embryo vascular system normally established already after 2-5 days [79].

For xenotransplantation, fertilized chicken eggs e.g., White Leghorn (Gallus domesticus) are purchased from a hatchery and maintained at $37.8^{\circ} \mathrm{C}$ and a $60 \%$ relative humidity atmosphere for the whole incubation period. Upon arrival the eggs are carefully cleaned (e.g., by $70 \%$ ethanol solution) and incubation is started (EDD 0). After 4 days (EDD 4) of incubation the eggs are fenestrated and analyzed for fertilization by visual assessment of the CAM vascularization and heartbeat of the embryo. The shell access window is sealed to prevent contamination and the egg placed back into the incubator. Cancer cells are seeded on the CAM and a solid tumor, well interfaced to the extra-embryonic vascular system, forms within few days $[1,16]$. The viability of the embryos needs to be monitored daily by checking the CAM vasculature for blood flow, physiological embryo movement, and the growth of the chick embryo according to Hamburger and Hamilton [80].

\section{MAGNETIC RESONANCE IMAGING (MRI)}

With its versatile image contrast, MRI raised interest in imaging of chick embryos already in the 80s. In 1986, Bone et al. $[81,82]$ reported first three-dimensional MR microscopy on the live chick embryo. At a $1.5 \mathrm{~T}$ prototype system with dedicated gradient system and receive coil, they achieved a spatial resolution of $200 \times 200 \times 1200 \mu \mathrm{m}^{3}$ with T1 and T2 weighting, applying partial saturation (PS) and spin echo (SE) $3 \mathrm{D}$-Fourier imaging techniques (3D-FT). To minimize motioninduced image artifacts, the chick embryo was immobilized by placing the egg in ice chips between 20 (EDD 11) and 90 (EDD 15) minutes. Imaging was performed at room temperature. Even though the spatial resolution and hence the fidelity of the anatomical details was still limited, Bone et al. clearly showed the potential combination of in ovo imaging and MRI as basis for further MRI studies. Improvements in spatial resolution were 


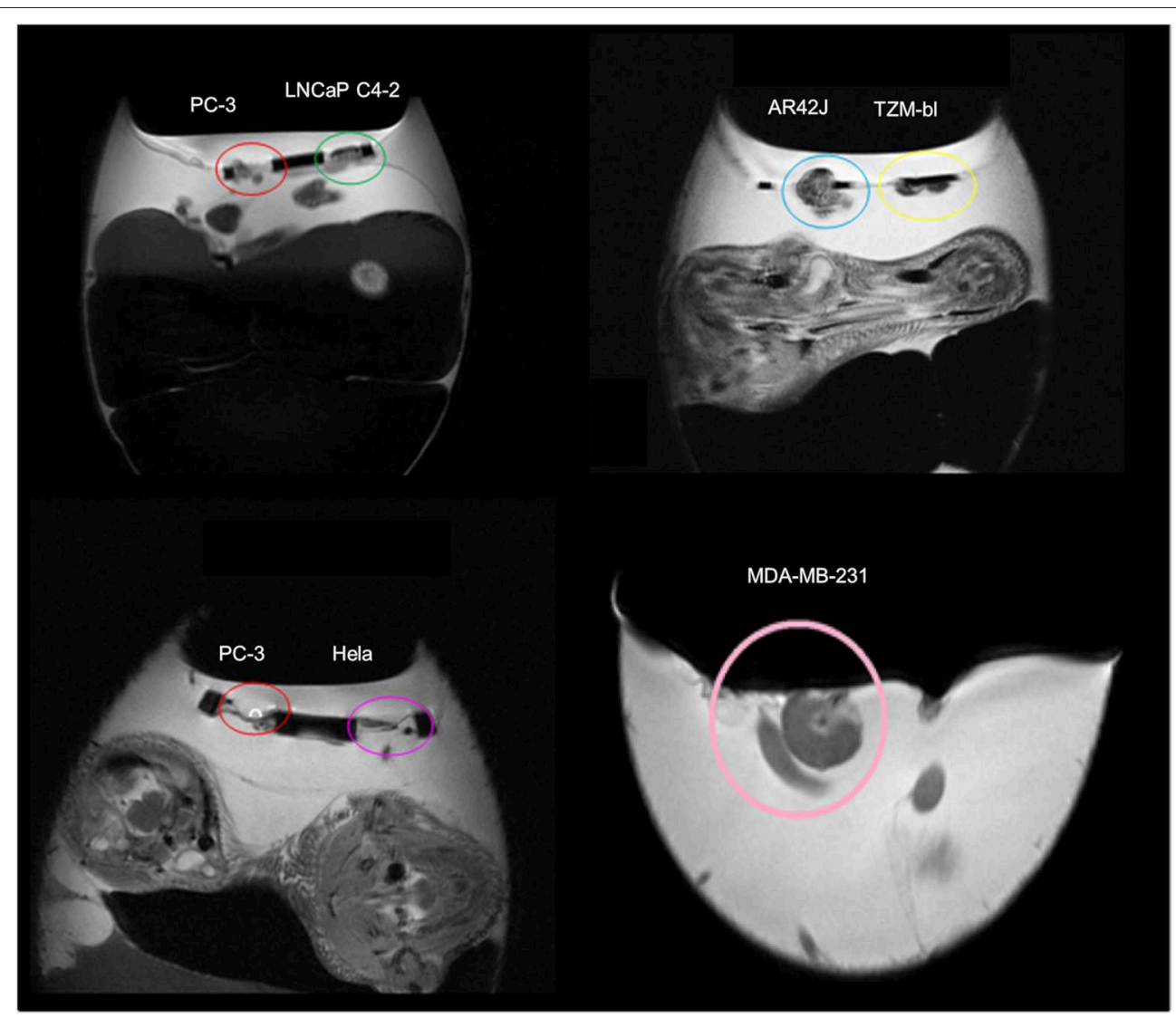

FIGURE 1 | Magnetic resonance images (MRI) of xenotransplanted tumors grown on the chorioallantoic membrane (CAM) from different cell lines (prostate cancer: PC-3, LNCaP C4-2; pancreas cancer: AR42J; adenocarcinoma: TZM-bl; cervical cancer: HELA; breast cancer: MDA-MB-231). Unpublished imaging material provided by Winter and $\mathrm{Li}$.

reported by Effmann et al. [83], who used an implantable $18 \mathrm{~mm}$ diameter RF coil wrapped around the chick embryo, inductively coupled to an outside MR receiver [84]. With the resulting gain in signal-to-noise ratio (SNR), the PS 3D-FT could provide images with spatial resolutions of up to $50 \times 50 \times 600 \mu \mathrm{m}^{3}$ within $1-2 \mathrm{~h}$ scan times.

Assessment of metabolic developments by phosphorus ${ }^{31} \mathrm{P}$ MR spectroscopy (MRS) in correlation with anatomic developments were first reported by Moseley et al. in 1989 [54], who could clearly demonstrate the decrease of the observable ${ }^{31} \mathrm{P}$ volume by $80 \%$ indicating the respective tissue uptake. Further spectroscopy work was performed by Lirette et al. [85] for longitudinal quantification of the fat/water ratio $\left({ }^{1} \mathrm{H}\right.$ MRS) and the phosphormono-/phosphordiester ratio $\left({ }^{31} \mathrm{P}\right.$ MRS). Data were acquired with a $5 \mathrm{~cm}$-diameter surface coil, in which the eggs were placed centrally. Acquisition times were below $1 \mathrm{~h}$. Embryo motion was controlled by applying $1-2 \%$ halothane during scanning. Peebles et al. [86] applied ${ }^{1} \mathrm{H}$ MRS for monitoring of brain metabolites and diffusion MRI for assessment of changes in the apparent diffusion coefficient (ADC) in the brain during hypoxia. Immobilization of the chick embryo was achieved by dropping $5.0 \mathrm{mg}$ Ketamine onto the CAM. Single voxel MRS of $6 \times 6 \times 6 \mathrm{~mm}^{3}$ volumes of interest were acquired in about 30 minutes acquisition time, with subsequent acquisition of the diffusion MRI by a two-point method with $230 \times 230 \mathrm{x}$ $2000 \mu \mathrm{m}^{3}$ resolution.

Falen et al. [53] and Hutchison et al. [87] applied MRI with $\mathrm{T} 1$ and $\mathrm{T} 2-$ weighted imaging techniques to the assessment of the yolk structure. Both reported the applicability of MRI for the assessment of the morphology of yolk, albumen, air space, and eggshell. The inner structure of the yolk, including concentric yolk rings, could be clearly visualized by this non-destructive imaging technique. In 2000, Donoghue et al. [88] reported the application of MRI for monitoring residue transfer into egg yolk. After injection of Gd-DTPA, the transfer of the drug into the yolk was monitored by scanning the egg applying a T1-weighted (MPRAGE) sequence. It could be shown that Gd-DTPA residues were incorporated into the yolk ring structure.

Assessment of the chick embryo vasculature by MRI was reported by Smith et al. in 1992 [89]. They performed ex vivo high-resolution MRI of the embryonic vasculature after perfusion fixation of the vasculature structure with gadoliniumdoped gelatin. A similar approach was chosen by Hogers et al. [52] to demonstrate the benefit of ultra-highfield imaging by 
A



C

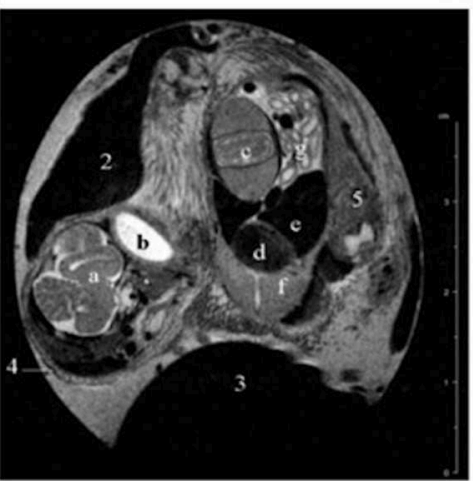

E

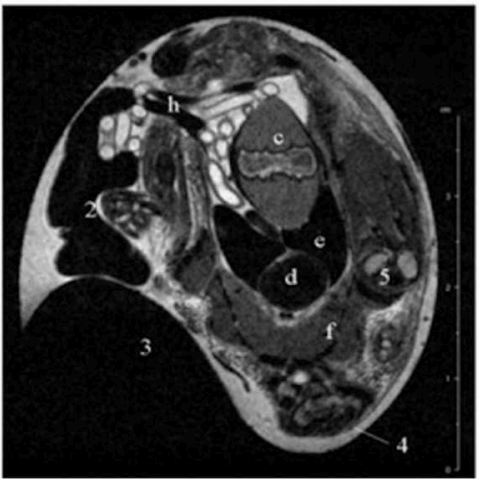

B

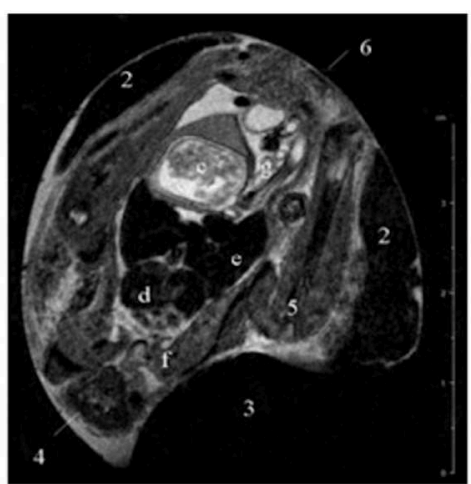

D



$\mathbf{F}$

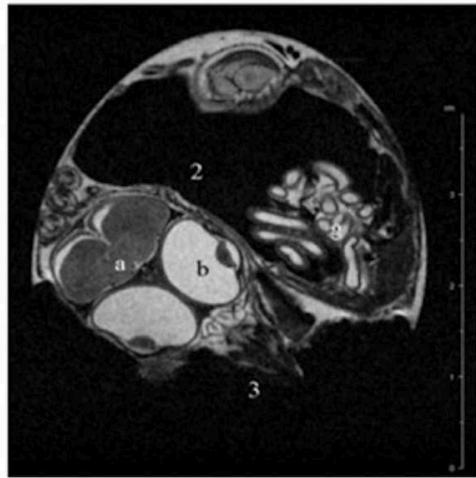

FIGURE 2 | Representative examples of T2-weighted multislice scans of chick embryos in ovo at (A) 12, (B) 15, (C) 17, (D) 18, (E) 19, and (F) 20 days of incubation. 1, albumen; 2, yolk; 3, air sac; 4, head; 5, limb; 6, rump; a, brain; b, eye; c, gizzard; d, heart; e, liver; f, pectoral muscles; g, intestine; h, umbilical vessels. The complete scans can be viewed at www.gla.ac.uk/7tmr/chickegg.htm. This research was originally published in JMRI: Noninvasive Monitoring of Chick Development In Ovo Using a 7T MRI System From Day 12 of Incubation Through to Hatching. Bain et al. [51].

comparing MRI in vitro microscopy between 7T and $17.6 \mathrm{~T}$ field strength. A similar ex vivo technique was applied by Zhang et al. [90] and Yelbuz et al. [91, 92], who used the combination of perfusion with immersion fixation and a small molecular gadolinium agent to improve image contrast between the myocardial wall and heart lumen. Isotropic three-dimensional images with up to $25^{3} \mu \mathrm{m}^{3}$ spatial resolution were acquired with a T1-weighted spin warp technique in about $29 \mathrm{~h}$ scan time at 9.4T field strength. In ovo quantification of the cardiac function was reported by Holmes et al. [93, 94] applying a self-gating technique for cardiac synchronization of the data. Even though adequate image quality could be obtained, the authors identified the bulk embryo motion at earlier stages as main limiting factor for reproducible image quality.

Noninvasive monitoring of chick embryo development was reported by Bain et al. [51] in 2007. For optimal image contrast a T2-weighted spin echo technique (RARE) was applied yielding $195 \times 195 \times 500 \mu \mathrm{m}^{3}$ spatial resolution within 25 minutes scan time at 7T (Figure 2). Rapid three-dimensional T1-weighted techniques provided higher spatial resolution, but organ contrast was not sufficient. For chick embryo immobilization, Bain et al. [51] used a precooling protocol, keeping the chicken eggs at 

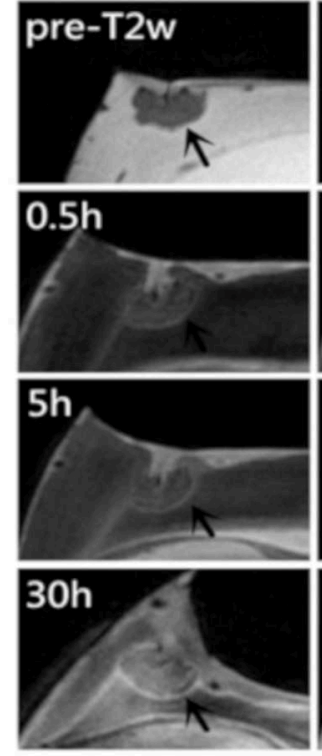
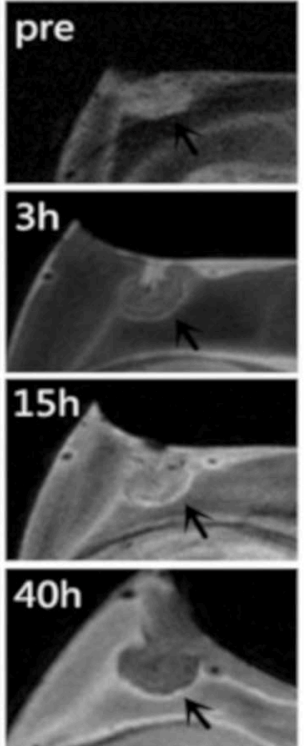


FIGURE 3 | Representative MR images of cHSA-PEO(2000)16-Gd biodistribution in solid tumor (left) and comparison of the SNR (Signal-to-Noise Ratio) of the tumor (right) over the first $40 \mathrm{~h}$ after systemic injection of CHSA-PEO(2000)16-Gd and Gd-DOTA. This research was originally published under the terms of the CC BY license (Creative Commons Attribution 4.0 International License) in Sci Rep: The CAM cancer xenograft as a model for initial evaluation of MR labeled compounds. Zuo et al. [65].

$4^{\circ} \mathrm{C}$ for $60 \mathrm{~min}$ prior to data acquisition with subsequent data acquisition at room temperature. No slowdown or arrest of the chick embryo development was observed by the cooling or the MRI examinations. As alternative cooling protocol, Li et al. [95] suggested data acquisition at $19^{\circ} \mathrm{C}$ thus enabling scan times of up to 4 hours in quail embryos. More advanced imaging techniques including $\mathrm{T} 1$ and T2 mapping as well as magnetization transfer ratio (MTR) quantification were reported by Boss et al. [50]. Motion reduction was achieved by application of $0.5 \mathrm{~mL}$ Ketamine onto the CAM. Images were acquired with two-dimensional multi-slice techniques at a spatial resolution of $180 \times 180 \times 1000 \mu \mathrm{m}^{3}$ (T1), $260 \times 260 \times 1000 \mu \mathrm{m}^{3}$ (T2), and $230 \times 230 \times 1000 \mu^{3}$ (MTR). In 2015, Zhou et al. [49] translated developmental imaging of the brain to a $3 \mathrm{~T}$ clinical scanner equipped with a dedicated small animal coil. T2 weighted RARE images as well as DTI data could be acquired at reasonable spatial resolution (T2w: $170 \times 170 \times 1000 \mu \mathrm{m}^{3}$ in 8 minutes, DTI: $1.25 \times 1.25 \times 1 \mathrm{~mm}^{3}$ in 6 minutes), enabling noninvasive analysis of brain development including structural information. Imaging of the chick embryo brain development after Zika virus infection was reported by Goodfellow et al. [96], who could clearly demonstrate Zika virus induced microcephaly. Highresolution MRI at 7T were presented by Lindner et al. [48] for monitoring the chick embryo eye development. Immobilization of the embryo was achieved by bedding the egg on crushed ice ten minutes before scanning.

A first application of in ovo MRI for the assessment of the biodistribution of new compounds was reported by Dingman et al. [97] in 2003. They longitudinally investigated the distribution of a 19F-labeled L-6-heptafluorobutyryl-5hydroxytryptophan including uptake dynamics and crossing of the blood-brain barrier. In 2007, Oppitz et al. [98] suggested the use of chick embryo model for evaluation of the advantages and limitations of MRI to monitor the migration of superparamagnetic iron oxide (SPIO) labeled cells. A similar approach was presented by Pereira et al. [99] who showed in the chick embryo model an improved sensitivity for in vivo cell tracking after implantation by supplementing the culture medium with adequate iron sources as compared to the use of reporter genes. Faucher et al. [100] used the HET-CAM model for initial investigation of ultra-small gadolinium oxide nanoparticles for labeling of glioblastoma cells, seeded on the CAM. Taylor et al. [101] used the chick embryo model for initial evaluation of new nano- and micro-sized magnetic particles for cell tracking. All imaging was performed ex vivo. In 2017, Zuo et al. [65] reported the use of human cancer cell lines xenotransplanted onto the CAM for initial assessment of the biodistribution of MR labeled drugs. After injection of GdDOTA, the biodistribution of the compound in the chick embryo as well as in the xenotransplanted tumor was observed. By longitudinal imaging studies over $40 \mathrm{~h}$, the accumulation and clearance of the contrast agent could be monitored. The technique was applied for demonstrating the feasibility of the HET-CAM tumor model for monitoring the fate of new MR labeled drugs by following the image contrast after intravenous administration of a gadolinium-labelled polymeric nanoparticle at high spatial resolution, applying an immobilization protocol as suggested earlier [61]. In direct comparison with conventional contrast agents, a significantly prolonged retention time of the polymeric nanoparticle in the tumor could be shown (Figure 3). For assessment of the intra-tumor distribution, 3D T1 weighted data were acquired at high spatial resolution of $100 \times 100$ 

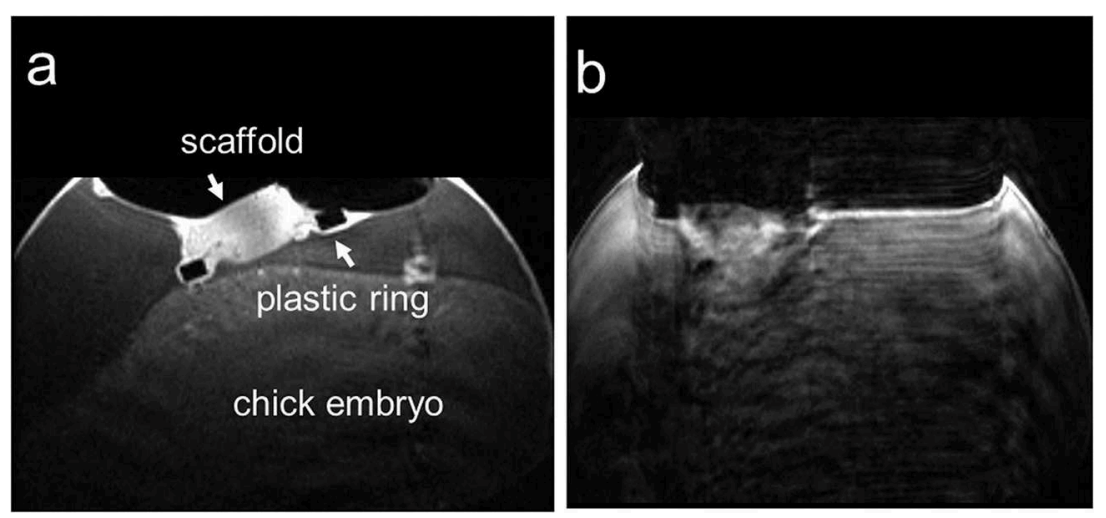

FIGURE 4 | Two in ovo T1-weighted MR images of the chick embryo on ID 14, seven days post-implantation on the CAM acquired in an axial slice through the biomaterial scaffold; (a) image without motion artifact and (b) image with motion artifacts that was excluded from further analysis. This research was originally published under the terms of the CC BY license (Creative Commons Attribution 4.0 International License) in Sci Rep: Comparison of medetomidine, thiopental and ketamine/midazolam anesthesia in chick embryos for in ovo Magnetic Resonance Imaging free of motion artifacts. Waschkies et al. [106].

x $560 \mu \mathrm{m}^{3}$. Hafner et al. [102] used a similar approach for initial evaluation of the biodistribution of a multifunctional drug carrier.

Buschmann et al. [103] reported implantation of human osteoblasts-seeded scaffolds onto the CAM. One week after xenotransplantation, MRI (T1, T2 quantification) analysis was performed ex vivo, after intravenous injection or dripping of gadolinium onto the scaffold before sacrificing the embryo allowing for the analysis of the formation of new capillaries. The published ex vivo data clearly indicated the potential of the HET-CAM model as cheap reliable model for monitoring the angiogenesis in tissue-engineering. This work was further developed by Chesnick et al. [104] by initial testing of a new adrenolate labeled gadolinium complex for specific targeting to bone mineral. In 2015, Pfiffner et al. [105] presented in vivo MRI at 4.7T to noninvasively quantify and monitor the perfusion capacity in the HET-CAM model. After placing a biomaterial on the CAM, its perfusion capacity was quantified by relaxation rate changes after intravenous injection of the gadolinium-based contrast agent. Immobilization of the chick embryo was achieved by 5 drops of ketamine 1:100 (Ketasol-100, Graeub, Switzerland) dripped onto the CAM surface. Anatomical reference images were obtained applying a FLASH sequence at measured spatial resolution of roughly $500^{2} \mu \mathrm{m}^{2}$. T1 and T2 maps were derived applying RARE sequences with multiple repetition times (TR) and echo times (TE) at spatial resolution of $200 \times 200 \times 1000 \mu \mathrm{m}^{3}$ before and at different time points after intravenous injection of $100 \mu \mathrm{L}$ Gd-DOTA (0.5M) MRI contrast agent. Relaxation rate changes over the scaffold could be clearly assessed indicating different vascular density, which was confirmed by histology.

Motion artifacts introduced by bulk motion of the chick embryo is a major limiting factor for high-resolution imaging of the CAM (Figure 4). In 2015, Waschkies et al. [106] investigated the use of different anesthesia drugs for immobilization, whereas Zuo et al. [61] evaluated an age-adjusted precooling protocol for high-resolution imaging of the CAM. In Waschkies et al, medetomidine at a dosage of $0.3 \mathrm{mg} / \mathrm{kg}$, was compared to thiopental at $100 \mathrm{mg} / \mathrm{kg}$ and ketamine/midazolam at 50 and $1 \mathrm{mg} / \mathrm{kg}$. The soluble anesthetics were applied by dropping a total volume of $0.3 \mathrm{~mL}$ onto the surface of the CAM. It was demonstrated that medetomidine performed best, enabling motion-free MRI for a period of about $30 \mathrm{~min}$ starting $10 \mathrm{~min}$ after application. Ketamine/midazolam yielded insufficient depth of anesthesia and thiopental anesthesia did not immobilize the chick embryo sufficiently long. In contrast, Zuo et al. investigated the use of an anesthesia-free immobilization approach. As extension to earlier published work [51], they suggested adaptation of the precooling time according to the age of the chick embryo, thereby achieving almost complete immobilization of the chick embryo for at least $60 \mathrm{~min}$ thus allowing multi-contrast high-resolution imaging of the chick embryo and xenotransplanted tumors on the CAM (Figures 5, 6). The suggested cooling protocol allowed in vivo imaging at high spatial resolution as $77 \times 91 \times 500 \mu^{3}$ (T2 weighted anatomic, 2D), $200 \times 200 \times 500 \mu \mathrm{m}^{3}$ (diffusion weighted, 2D), $104 \times 98 \times 500 \mu^{3}$ (T2 mapping, 2D), and $100 \times 100 \times 560 \mu^{3}$ (T1 weighted, 3D). Tumor volume and growth could be monitored longitudinally from day 4 to day 9 after xenotransplantation. The tumor progression could be monitored for each individual case (Figure 7) and the volumes derived from MRI at day 9 excellently correlated with the respective volumes derived after resection of the tumors. In 2018, Herrmann et al. [58] reported the application of MRI to measure primary neuroblastoma tumor size and metastasis in a chick embryo model. Human neuroblastoma cells labeled with green fluorescent protein (GFP) and micron-sized iron particles were xenotransplanted on the CAM at EDD 7. At EDD 14, T2 RARE and T2-weighted fast low angle shot (FLASH) data were acquired (Figure 8) using the cooling protocol as suggested by Zuo et al. [61]. Additionally, Herrmann et al. performed timeof-flight (ToF) MR angiography (MRA) and reported a reduced blood flow if using the cooling protocol, making successful ToF acquisition unfeasible. Instead, ketamine anesthesia $(3.6 \mathrm{mM}$ ketamine in $500 \mu \mathrm{L}$ PBS) was applied resulting in MRI data free 




FIGURE 5 | Comparison between different image resolution: (a) $77 \times 91 \mu^{2}{ }^{2}$, (b) $200 \times 200 \mu \mathrm{m}^{2}$, and (c) $500 \times 500$. With increasing resolution, details of e.g., the pulmonary veins (1), the beak (2, axial orientation), and tumor tissues (3) could be clearly resolved. Insets show details of the respective target structures. This research was originally published in NMR Biomed: High-resolution MRI analysis of breast cancer xenograft on the chick chorioallantoic membrane. Zuo et al. [61].

of motion artifacts for a period of $30 \mathrm{~min}$. The micron-sized iron labeling of the cells allowed in ovo assessment of the primary tumor and detection of metastatic deposits.

\section{POSITRON EMISSION TOMOGRAPHY (PET)}

Most anatomic and functional imaging of the HET-CAM model has been performed by MRI so far. The main limitation of PET results from its rather low spatial resolution, which does not fit the high spatial resolution demands for imaging of the CAM. To gain from the outstanding sensitivity of PET, thus in almost all work published, PET (or SPECT) imaging was complimented by Computer Tomography (CT), x-ray, or MRI for providing additional anatomic details.

In 2012, Würbach et al. [71] introduced using ${ }^{18} \mathrm{~F}$-fluoride PET for assessment of bone metabolism. For radionuclide injection, a self-built catheter made of a $30 \mathrm{G}$ needle and a polythene tube with $0.28 \mathrm{~mm}$ inner diameter was introduced into one of the CAM vessels. Imaging was performed for a period of roughly 75 minutes yielding dynamic images (55 time frames) as well as high-quality static data. Applying an iterative ordinary Poisson maximum a posteriori reconstruction yield voxel sizes of roughly $400 \times 400 \times 800 \mu \mathrm{m}^{3}$. The results proved the quantitative and reproducible assessment of bone metabolism in anesthetized chick embryos. Immobilization of the chick embryo during scanning was achieved by exposing the CAM to isoflurane at $1.5 \%$ concentration as suggested by Heidrich et al. [107], who investigated different anesthesia schemes for in vivo imaging of avian embryos, including isoflurane, 2,2,2-tribromoethanol (Avertin), and urethane/ $\alpha$ chloralose (UC). UC and Avertin were directly applied as liquids onto the CAM. For isoflurane anesthesia, the egg was exposed to an isoflurane concentration of $5 \%$ in oxygen. For induction, the eggs were placed into a narcosis induction chamber. Toxic side effects and only poor correlation between narcosis depth and dose limited the application of UC and Avertin and the authors clearly favored the use of Isoflurane due to its high tolerability enabling repeated imaging of the avian embryos at a daily basis. In 2013, Gebhardt et al. [70] applied a similar approach as Würbach et al. [71] to initially 


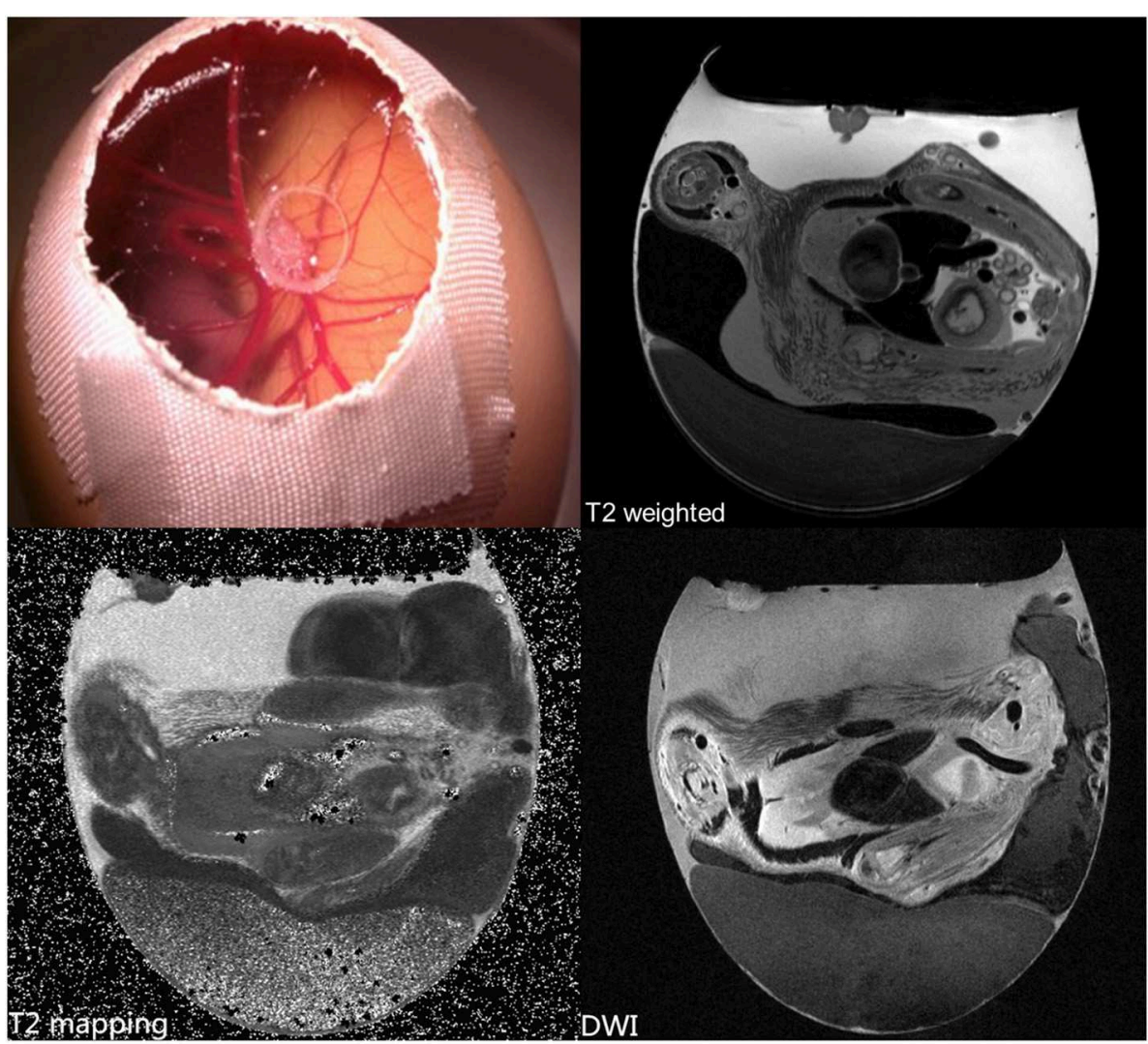

FIGURE 6 | In vivo high-resolution MRI with T2 and diffusion weighting (DWI), and T2 quantification of a Human breast tumor (carcinoma cell line MDA-MB-231) xenotransplanted on the CAM. Unpublished imaging material provided by Zuo obtained with precooling and MR protocols as described in [61].
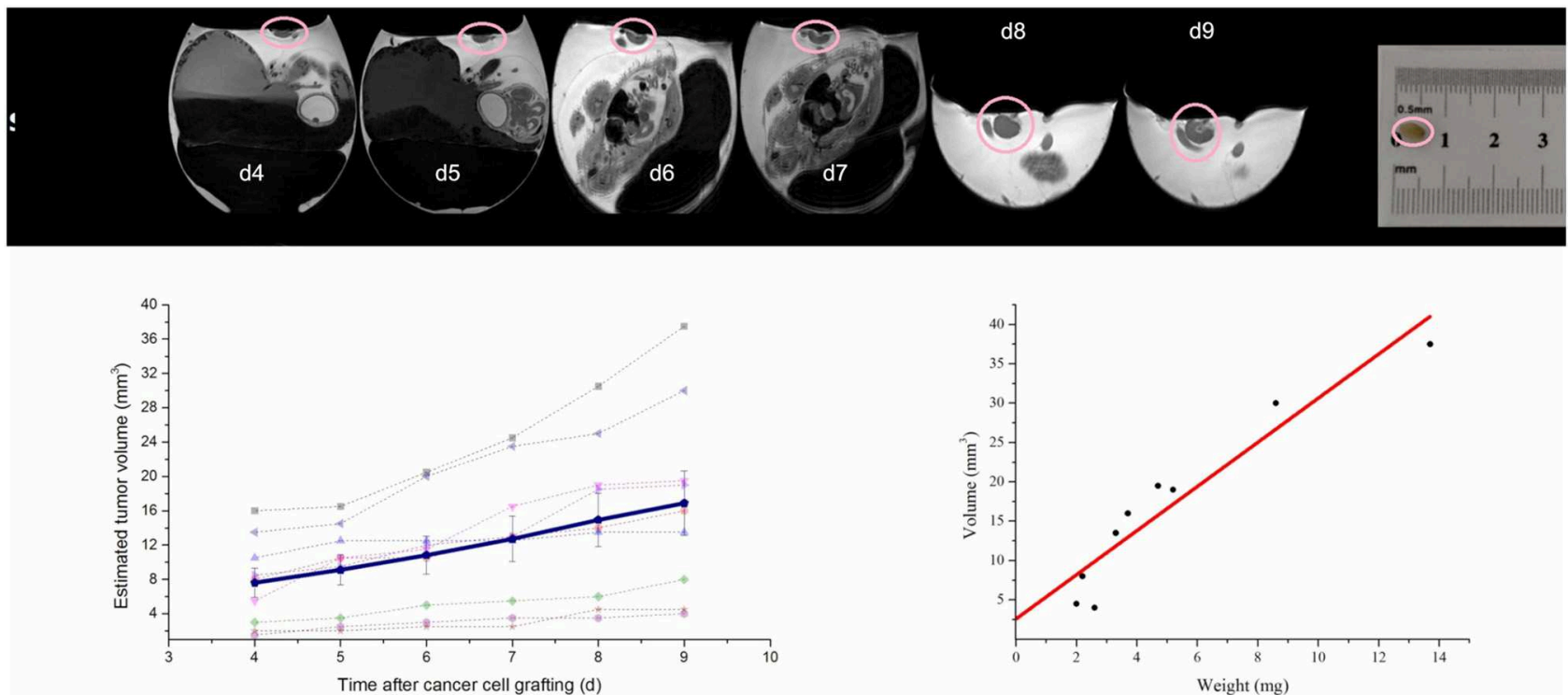

FIGURE 7 | Monitoring the progression of xenotransplanted tumor (circle) from day 4 to day 9 after cell seeding on the CAM. (Top) High-resolution T2 weighted MR images; (lower left) individual tumor volumes $(n=9)$ and mean volume progression (solid line); (lower right) correlation of tumor volume ( $n=9$ ) and weight after tumor resection at day 9. Modified from original research published in NMR Biomed: High-resolution MRI analysis of breast cancer xenograft on the chick chorioallantoic membrane. Zuo et al. [61]. 
A

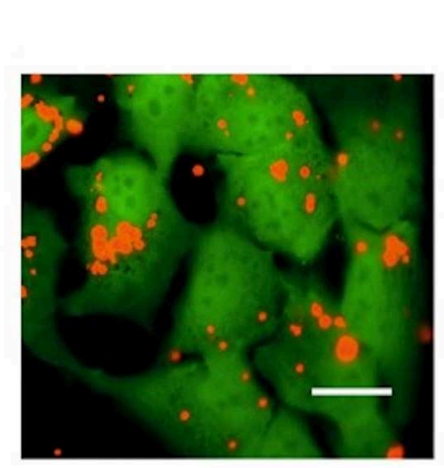

C

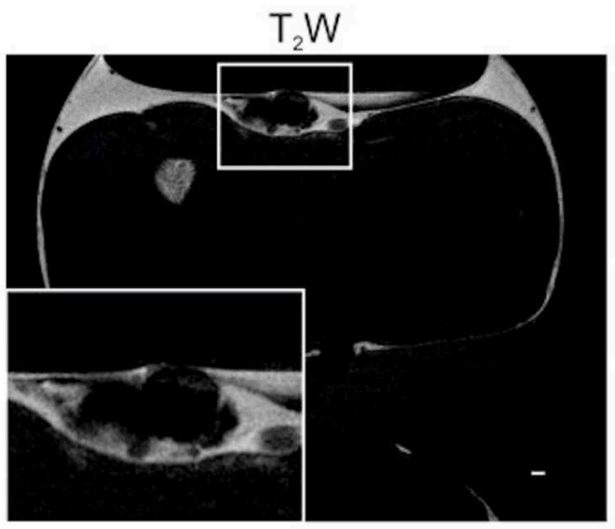

D

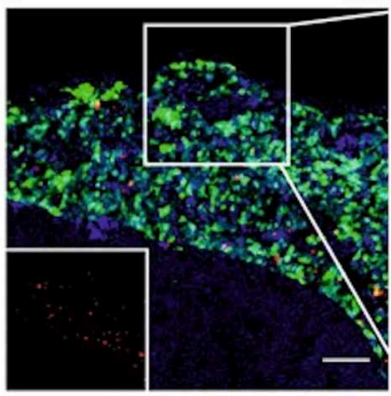

B
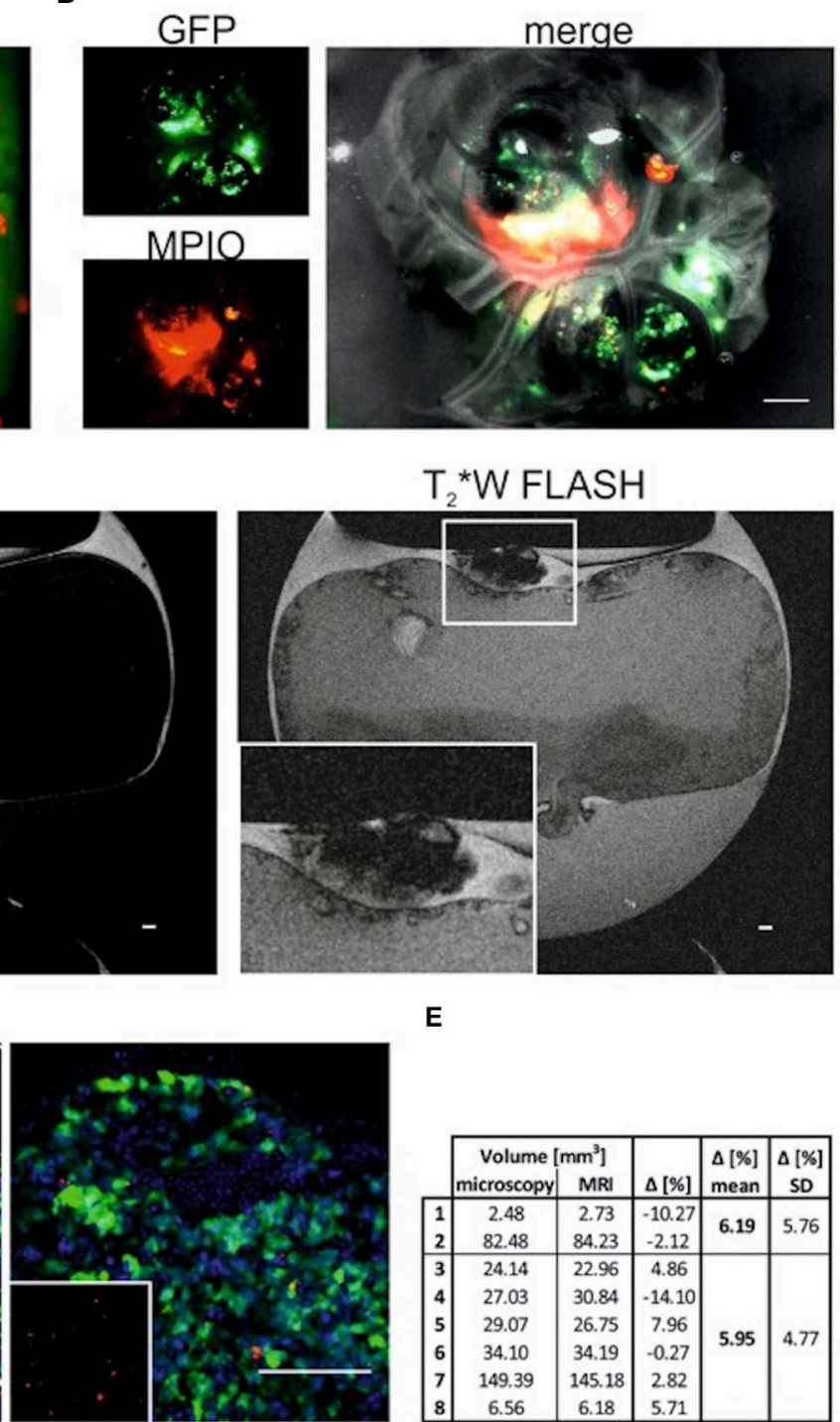

E

\begin{tabular}{|c|c|c|c|c|c|}
\hline & \multicolumn{2}{|c|}{ Volume $\left[\mathrm{mm}^{3}\right]$} & \multirow[b]{2}{*}{$\Delta[\%]$} & \multirow{2}{*}{$\begin{array}{l}\Delta[\%] \\
\text { mean }\end{array}$} & \multirow{2}{*}{$\begin{array}{c}\Delta[\%] \\
\text { SD }\end{array}$} \\
\hline & microscopy & MRI & & & \\
\hline 1 & 2.48 & 2.73 & -10.27 & \multirow{2}{*}{6.19} & \multirow{2}{*}{5.76} \\
\hline 2 & 82.48 & 84.23 & -2.12 & & \\
\hline 3 & 24.14 & 22.96 & 4.86 & \multirow{6}{*}{5.95} & \multirow{6}{*}{4.77} \\
\hline 4 & 27.03 & 30.84 & -14.10 & & \\
\hline 5 & 29.07 & 26.75 & 7.96 & & \\
\hline 6 & 34.10 & 34.19 & -0.27 & & \\
\hline 7 & 149.39 & 145.18 & 2.82 & & \\
\hline 8 & 6.56 & 6.18 & 5.71 & & \\
\hline
\end{tabular}

FIGURE 8 | T2W and T2*W FLASH images of tumors labeled with MPIO (A) GFP-expressing SK-N-AS cells (green) $24 \mathrm{~h}$-postlabeling with $20 \mathrm{mM}$ MPIO (Suncoast Yellow Encapsulated Magnetic Polymers-Bangs Beads, Red). Scale bar is $20 \mathrm{~mm}$. (B) Single channel and overlay image of neuroblastoma tumor postdissection formed by GFP-expressing SK-N-AS cells (green) which were labeled with MPIO (red) $48 \mathrm{~h}$ prior CAM implantation. Scale bar is $1000 \mathrm{~mm}$. (C) Representative sagittal T2Wand T2*W FLASH MRI images of embryonated chicken egg at E14 (A). Tumor formed by cells labeled with MPIO can be identified on top of the CAM (zoom in inset). Scale bar is $1000 \mathrm{~mm}$. (D) Representative image of tumor formed on the CAM by GFP-expressing SK-N-AS cells (green) labeled with MPIO (red). Nuclei are stained with Hoechst (blue). Inset shows MPIO only (red). Right image is 2.5_zoom. Scale bar is $100 \mathrm{~mm}$. (E) Comparison of tumor volume (mm3) measured by microscopy or MRI. Tumors 1 to 2 were formed by cells without MPIO, tumors 3 to 8 . This research was originally published under the terms of the CC BY license (Creative Commons Attribution 4.0 International License) in Mol Imaging: Magnetic Resonance Imaging for Characterization of a Chick Embryo Model of Cancer Cell Metastases. Herrmann et al. [58].

evaluate the dynamic behavior of new PET tracers in the chick embryo model as an in vivo assay. Various ${ }^{18} \mathrm{~F},{ }^{64} \mathrm{Cu}$, and ${ }^{68} \mathrm{Ga}$-labeled compounds were investigated and the potential of the chick embryo model as efficient in vivo model could be shown.

Warnock et al. [69] demonstrated the use of the CAM for screening of novel PET tracers. At EDD 11, the eggs were opened and $5 \times 10^{6}$ human U87 glioblastoma cells in $20 \mu \mathrm{L}$ of culture medium xenotransplanted onto the CAM. At EDD 18 PET/CT imaging of the tumors was performed. During scanning the egg was reproducible positioned in both systems in a small animal imaging cell (Minerve equipment veterenaire) allowing temperature control and isoflurane anesthesia (2\% in air). Uptake of the radiotracer was clearly demonstrated by timeactivity curves and in the PET images (Figure 9). Contrast-agent enhanced $\mu \mathrm{CT}$ data provided accurate anatomic correlation, 


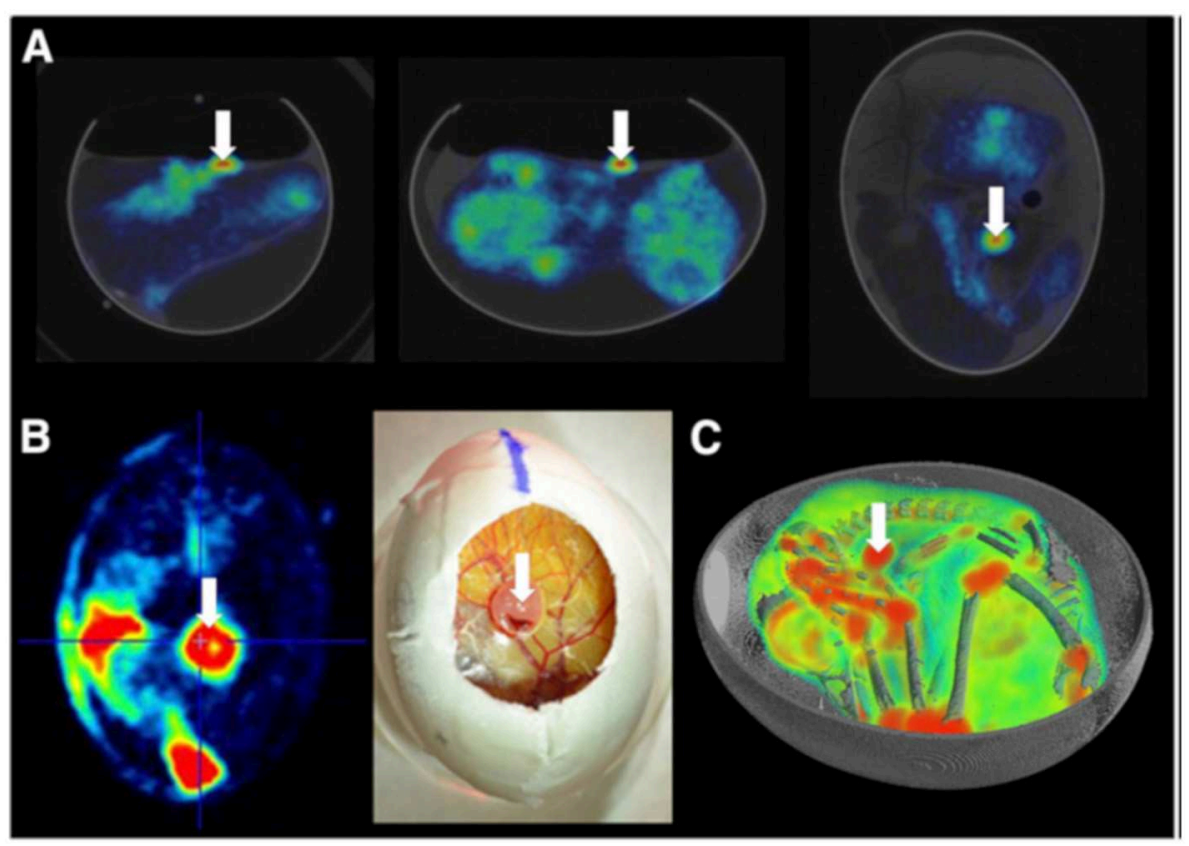

FIGURE 9 | (A) Two-dimensional coregistered PET and CT images of the chicken egg after $\left[{ }^{18} \mathrm{~F}\right]$-FDG injection and 45 min tracer uptake. (B) Visual comparison of 18F-FDG uptake in glioblastoma at level of CAM to photograph illustrating tumor localization. (C) $3 \mathrm{D}$ visualization of overlaid PET and CT images for [ ${ }^{18} \mathrm{~F}$-FDG uptake in embryo and U87 human glioblastoma tumor (white arrow). This research was originally published in JNM: in vivo PET/CT in a human glioblastoma chicken chorioallantoic membrane model: a new tool for oncology and radiotracer development. Warnock et al. @ by the Society of Nuclear Medicine and Molecular Imaging, Inc. [69].

enabling distinction of the uptake in the joints and the tumor. Their outcome clearly indicated the potential of the suggested HET-CAM model for initial assessment of the pharmacokinetics of new compounds.

Haller et al. [19] investigated the tissue distribution and stability of different ${ }^{18} \mathrm{~F},{ }^{125} \mathrm{I},{ }^{99 \mathrm{~m}} \mathrm{Tc}$, and ${ }^{177} \mathrm{Lu}$-labeled radiopharmaceuticals. For imaging purposes the chick embryos were euthanized by shock-freezing in liquid nitrogen at different time points after administration of the radioactivity. In comparison with the established mouse models, they concluded a similar tissue distribution and stability of radiopharmaceuticals in the chick embryo. The very similar behavior in the two in vivo models indicate the potential of using the chick embryo as an inexpensive and simple test model for preclinical screening of novel radiopharmaceuticals. To overcome the limitations of the small anatomies with respective requirement of dedicated highresolution imaging equipment, Freesmeyer et al. [108] suggested the translation of the work into ostrich eggs and demonstrated the potential use for different radiotracers even on conventional PET/CT systems. Even though overcoming the issues with small anatomy and high-spatial resolution requirements, ostrich eggs cannot be seen as a real alternative to chick embryos, since they are not readily available, hardly established in science, expensive and often do not fit into conventional small animal imaging equipment.

In a recent work of Zlatopolskiy et al. [68] the HET-CAM model was used for evaluation of radiotracers addressing the tryptophan metabolic pathway. An efficient method for the synthesis of fluorotryptophans, labeled in different positions with ${ }^{18} \mathrm{~F}$ is presented and their biological evaluation regarding tumor targeting evaluated in the HET-CAM model. Therefor MCF7, PC-3, and NCI-H69 xenografts were cultivated on the CAM. The tissue distribution of the new agent $7-\left[{ }^{18} \mathrm{~F}\right] \mathrm{FTrp}$ in comparison to conventional ${ }^{18} \mathrm{~F}^{-}$ was assessed after systemic injection. While in the ${ }^{18} \mathrm{~F}$-scans tracer uptake was mainly observed in bones, joints, and beak of the chick embryos, $7-\left[{ }^{18} \mathrm{~F}\right]$ FTrp clearly delineated the tumor.

Even though CT represents an important imaging tool providing relevant anatomic information and has proven clinical success in combination with PET, its only limited soft tissue contrast is often insufficient. To that respect in 2019 Steinemann et al. [109] and Winter et al. [110] combined in ovo PET with MRI to make full advantage from the high sensitivity of PET and the excellent soft tissue contrast in MRI. Steinemann et al. used the imaging approach for monitoring the effectiveness of a new chimeric inhibitor (animacroxam, which combines histone deacetylase (HDAC) inhibitory and cytoskeleton-interfering pharmacophores) to the clinical approved HDAC in testicular germ cell tumor. Tumor plaques were grown from $10 \times 10^{6} 2102 \mathrm{EP}$ cells mixed with $150 \mu \mathrm{l}$ matrigel and transplanted onto the CAM. Imaging was performed three days after xenotransplantation to allow angiogenic connection of the xenograft to the CAM. Injection 


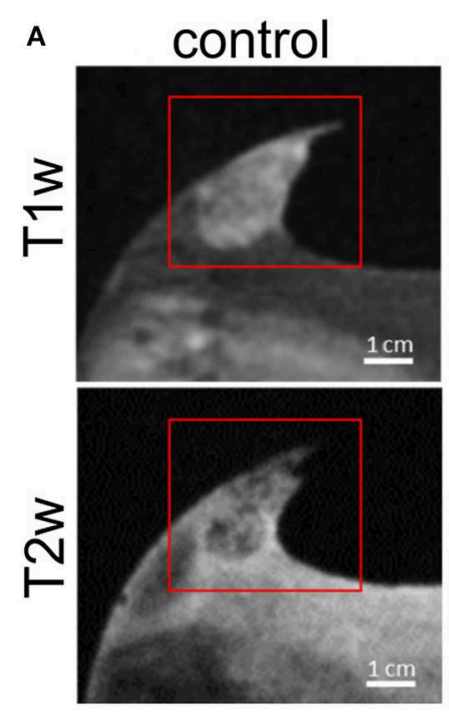

B

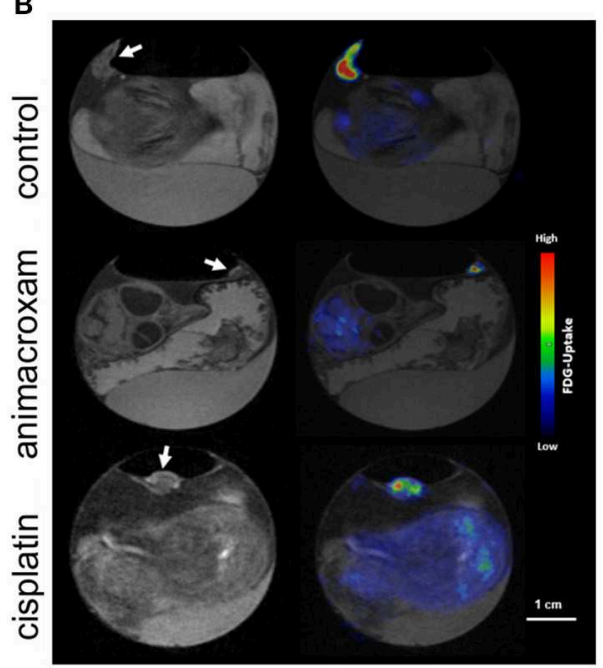

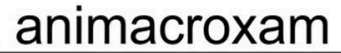
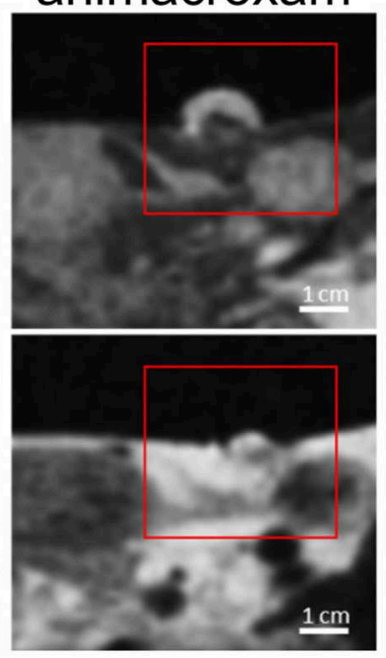

C
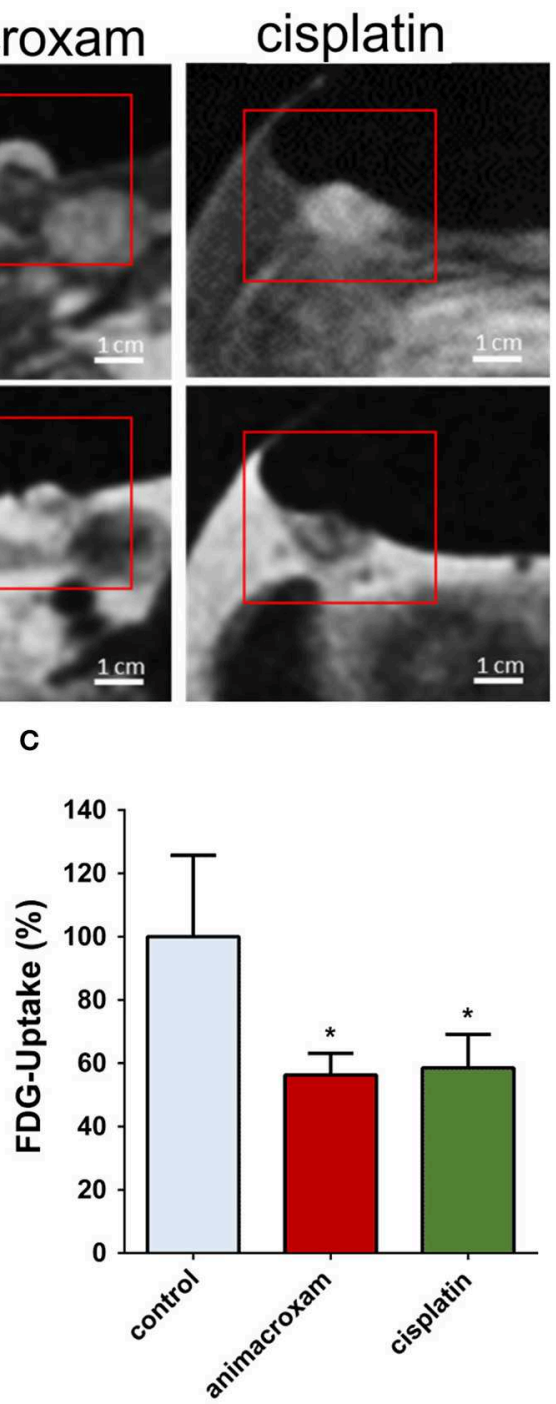

FIGURE 10 | Animacroxam induces 'cap formation' and suppresses glucose uptake in inoculated TGCT plaques. (A) T1w and T2w images of control-, animacroxam-, and cisplatin-treated tumor plaques. Animacroxam-treated tumors show a distinct viable tumor core (dark in T1w-/bright in T2w images) and a necrotic cap (bright in T1w-/dark in T2w images). (B) T1w and corresponding PET-MR images of [ $\left.{ }^{18} \mathrm{~F}\right]-\mathrm{FDG}$ uptake in tumor plaques treated with NaCl, animacroxam, or cisplatin. (C) Animacroxam $(5.0 \mu \mathrm{m})$ - and cisplatin $(2.5 \mu \mathrm{m})$-treated tumor plaques showed a reduced uptake of [ $\left.{ }^{18} \mathrm{~F}\right]$-FDG. Results are shown as means \pm SEM of at least $n=3$ independent experiments. Scale bar $=1 \mathrm{~cm}$. ${ }^{\star} P$-values of $\leq 0.05$, unpaired $t$-test. This research was originally published under the terms of the Creative Commons Attribution License (CC BY) in Molecular Oncology: Antitumor and antiangiogenic activity of the novel chimeric inhibitor animacroxam in testicular germ cell cancer, Steinemann et al. [109].

of the compounds [concentrations calculated assuming $1 \mathrm{~mL}$ blood volume: $5 \mu \mathrm{M}$ animacroxam, $2.5 \mu \mathrm{M}$ cisplatin, or $\mathrm{NaCl}$ $(0.9 \%)]$, was done intravenously via a $30 \mathrm{G}$ syringe. The tumor volume was derived from MRI measurements (3D T1w-GRE, $290 \times 290 \times 500 \mu \mathrm{m}^{3}$, TR/TE $=50 \mathrm{~ms} / 2.7 \mathrm{~ms} ; 2 \mathrm{D}$ RARE, $290 \times 290 \times 700 \mu \mathrm{m}^{3}, \mathrm{TR} / \mathrm{TE}=8885 \mathrm{~ms} / 100 \mathrm{~ms}$ ) prior and 7 days after treatment. Immobilization of the chick embryos was obtained by $1 \mathrm{~h}$ precooling. Tumors could be clearly delineated in the MRI data and respective volumes quantified. Respective glucose uptake of the tumors was assessed by $\left[{ }^{18} \mathrm{~F}\right]-\mathrm{FDG}$ PET imaging $(0.1 \mathrm{~mL}$ of $12 \mathrm{MBq})$. Fusion of the PET and MRI data showed excellent agreement between tumor extend and FDG uptake (Figure 10). The observed reduction in tumor volume under treatment correlated well with the observed reduced glucose uptake. Winter et al. evaluated the HETCAM for initial testing of the binding specificity of targeted compounds. They used the well-characterized PSMA-specific PET radiotracer $\left[{ }^{68} \mathrm{Ga}\right.$ ]-PSMA-11 to demonstrate the principle of the HET-CAM model for evaluation of specific radioligand accumulation in prostate cancer xenografts (Figure 11). At EDD 6, tumor cells of the PSMA-positive cell line LNCaP C4-2 (1 $\mathrm{x} 10^{6}$ cells) and the PSMA-negative control PC-3 $\left(7.5 \times 10^{5}\right.$ 




FIGURE 11 | PET/MRI for quantification of the PSMA-specific PET radiotracer [ $\left.{ }^{68} \mathrm{Ga}\right]-\mathrm{PSMA}-11$ in the HET-CAM model with dual tumor seeding (LNCaP C4-2, PSMAQ17 positive; PC-3, PSMA negative) (A). The tumors can be nicely visualized by high-resolution MRI (B, red circle). Distribution of the $\left[{ }^{68}\right.$ Ga]-PSMA-11 by PET reveals strong signal at one location of the CAM and some general accumulation in the chick embryo (C). Fusion of the PET and MRI data (D) reveals tracer accumulation in the PSMA positive tumor (red circle), which is proven by gamma counting after resection of the tumors (E). Unpublished imaging material provided by Winter G. and Li H.

cells) mixed in Matrigel (40\%, v/v) were grafted on the CAM in two silicon rings. MR and PET imaging was performed starting on EDD 12. Anatomical information was provided by high-resolution imaging using a small animal MR based on the protocol of Zuo et al. [61, 65]. For PET, $150 \mu \mathrm{l}$ of $\left[{ }^{68} \mathrm{Ga}\right]-P S M A-11$ solution was injected into a chorioallantoic membrane vessel followed by a dynamic 60 minutes PET scan. Registration between both imaging modalities was achieved by a self-built animal holder with PET and MRI visible fiducial markers. Tumor growth could be quantified by MR imaging. In addition to PET imaging the tumor entities were excised from the membrane after measurement and the accumulated activity was separately quantified by $\gamma$-counter (COBRA II, Perkin Elmer) detection. As expected, in comparison to the PC-3 tumors, higher accumulation of $\left[{ }^{68} \mathrm{Ga}\right]$-PSMA-11 was observed in the LNCaP C4-2 tumors, indicating the applicability of the HET-CAM model for initial testing of binding specificity of targeted compounds.

\section{DISCUSSION}

The HET-CAM model has been exerted to numerous applications. It represents a simple, quick, and low-cost model, not rising any regulatory concerns in many countries if sacrificed before hatching. However, there is a consensus in the scientific community that it is illogical to conclude that the neural capacity to experience pain is not fully developed prior to hatching and that beyond a critical point in development avian embryos are capable of experiencing pain. The exact stage of development at which this capacity is sufficiently developed to warrant concern has not yet been determined. Society recognizes that a critical period in chick embryo development occurs $72 \mathrm{~h}$ prior to hatching and from an ethical point of view embryos should be sacrificed prior to EDD 18.

Since the HET-CAM model represents a naturally immunodeficient host, xenotransplantation of many kinds of tumors without species-specific limitations are possible. Even considering the fact that not all organs are fully developed, the established circulation and the highly vascularized CAM, which is connected to the embryo through a continuous circulatory system make it a natural candidate in-between cell culture and animal experiments, especially for initial testing of new compounds. Even though not finally established, it will likely play an important role in early drug development as pointed out in Figure 12. Compounds without detectable toxicity in cell and eventually zebra fish assays, may be initially evaluated regarding efficacy and biodistribution in the HET-CAM model, thereby reinforcing the potential of this convenient, $3 \mathrm{R}$ compliant, in vivo 

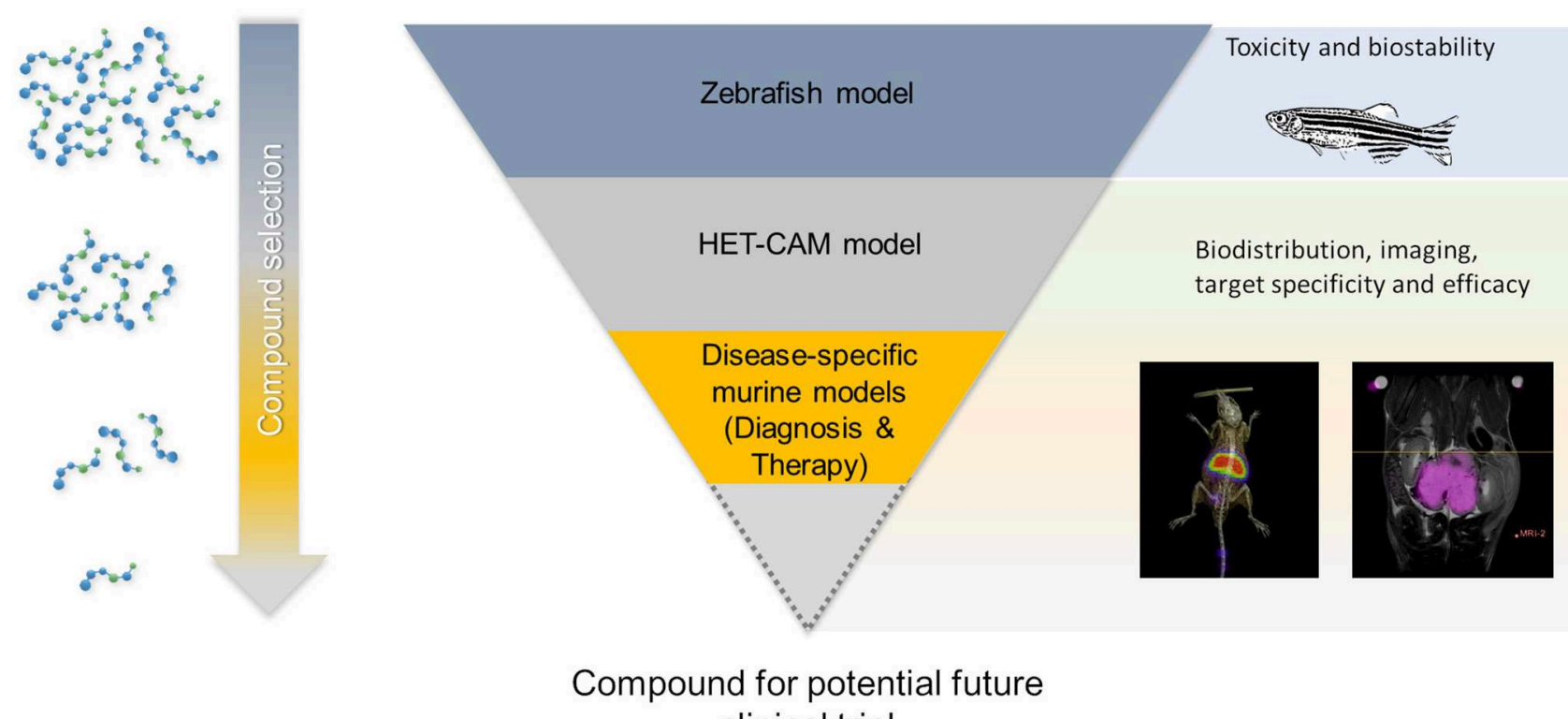

\section{Compound for potential future clinical trial}

FIGURE 12 | Potential role of PET-MRI imaging in the HET-CAM model within new drug developments.

model for cancer research. Only compounds showing promising properties will then further be evaluated in animal models, thus reducing the need for animal studies and related costs.

Non-invasive imaging will likely play an increasingly important role for direct visualization of the biodistribution of respectively labeled compounds and longitudinal monitoring of surrogate markers such as tumor progression and metabolism. MRI appears as an attractive imaging approach providing flexible image contrast and assessment to different tissue-specific parameters like MR relaxation times, diffusion and perfusion. Even though it offers the possibility of tailoring image contrast to the specific application, its intrinsic low sensitivity often limits its application in identification of small amounts or only traces of compounds. This limitation raises the increasing interest in using PET in the context of HET-CAM imaging. The excellent sensitivity of PET combined with the excellent anatomic detail of MRI appears as an ideal combination for anatomic, metabolic, and molecular imaging in the HET-CAM model.

Even though in PET motion compensation of the embryo may not be of paramount importance due to its only limited spatial resolution, in MRI coping with embryo motion is one of the major challenges to finally achieve the required highspatial resolution. Over the last years efficient immobilization approaches of the chick embryo have successfully been evaluated in ovo (Table 1). Promising approaches include the precooling of the egg prior to scanning, the application of halothane and isoflurane, and the use of anesthesia agents dropped directly onto the CAM. Good to excellent immobilization could be achieved with almost all approaches. Major differences were reported regarding immobilization duration and resulting possible image acquisition times, tolerability by the chick embryo, side effects, and easiness to use. For high-resolution anatomic imaging, precooling appears as an excellent approach, allowing long scan times of up to one hour and being easy-to-use. However, the related slowdown in metabolism [113] and blood flow [58] may limit its application in cases where physiological properties are under investigation. Here, in contrast to halothane, isoflurane was reported to not impact aortic blood flow and cardiac performance [114] and may be a good alternative with the limitation of a quite complex imaging setup. Both approaches are well tolerated by the chick embryo allowing for repeated measurements in longitudinal studies. Liquid anesthetics applied by directly dropping onto the CAM are easy to use and a variety of agents have been reported with widely varying anesthesia efficiency and often toxic side effects [58, 106, 107]. Even though, ketamine was reported to reduce cardiac contraction force in isolated chick embryo heart at EDD 4 and EDD 7 [115], Herrmann et al. reported the advantage of ketamine over precooling for time-of-flight MRI [58] and showed its possible use in applications being sensitive compromised circulation or metabolism in cases of rather short acquisition times.

This review specifically addresses MRI/PET imaging techniques for HET-CAM applications. Even though highly attractive for high-quality multi-contrast morphological and functional imaging in combination with high-sensitive imaging of radio-labeled compounds, both represent high-cost imaging techniques requiring long acquisition times with only limited applicability to high-throughput applications. A wide range of alternative somehow competing techniques have been proposed over recent years. Most prominent to mention at this point are 
TABLE 1 | Overview of reported in vivo in ovo imaging and spectroscopy studies.

\begin{tabular}{|c|c|c|c|c|c|c|c|c|}
\hline References & Modality & Application & Imaging technique & Dimension & Spatial resolution & Immobilization & EDD & Scan time \\
\hline Bone et al. [81] & $\begin{array}{l}\text { MRI }(1 \mathrm{H}, \\
1.5 \mathrm{~T})\end{array}$ & Embryonic anatomy & T1-/T2-weighted SE & $3 D$ & $\begin{array}{l}200 \times 200 \times 1200 \\
\mu m^{3}\end{array}$ & $\begin{array}{l}\text { Precooling (EDD } 1120 \\
\text { minutes, EDD15 } 90 \\
\text { minutes) on ice chips }\end{array}$ & 11,15 & Not reported \\
\hline Effmann et al. [83] & $\operatorname{MRI}(1 \mathrm{H}, 2 \mathrm{~T})$ & Embryonic anatomy & T1-weighted SE & $2 \mathrm{D}$ & $50 \times 50 \times 600 \mu \mathrm{m}^{3}$ & Not reported & $4,6,9$ & $1-2 \mathrm{~h}$ \\
\hline Moseley et al. [54] & $\begin{array}{l}\text { MRS }(31 \mathrm{P}, \\
2 \mathrm{~T}), \mathrm{MRI}(1 \mathrm{H}, \\
2 \mathrm{~T})\end{array}$ & $\begin{array}{l}\text { Metabolic (MRS) and } \\
\text { anatomic (MRI) } \\
\text { development }\end{array}$ & T1/T2-weighted SE & $\begin{array}{l}\text { Single voxel (MRS), } 2 \mathrm{D} \\
\text { (MRI) }\end{array}$ & $\begin{array}{l}\text { Whole egg (MRS) } 270 \\
\times 270 \times 2000 \mu \mathrm{m}^{3} \text { to } \\
350 \times 700 \times 3000 \\
\mu \mathrm{m}^{3}(\mathrm{MRl})\end{array}$ & Not reported & $\begin{array}{l}\text { 4, 9, 12, 15, 17, 18, } \\
\text { 19, 20, } 21 \text { (MRS), 5, } 9 \\
\text { 15, } 23 \text { (MRI) }\end{array}$ & $\begin{array}{l}20 \mathrm{~min} \text { (512 NSA, } \\
\text { MRS), not reported } \\
\text { (MRI) }\end{array}$ \\
\hline Lirette et al. [85] & $\begin{array}{l}\text { MRS (31P, } \\
1 \mathrm{H}, 2 \mathrm{~T})\end{array}$ & $\begin{array}{l}\text { Metabolic } \\
\text { development, fat-water } \\
\text { fraction }\end{array}$ & & Single voxel & Whole egg & Halothane & $\begin{array}{l}0,2,4,6,8,10,12 \\
14,16,17,19,20\end{array}$ & \\
\hline Peebles et al. [86] & $\begin{array}{l}\text { MRS }(1 \mathrm{H}, 7 \mathrm{~T}) \\
\operatorname{MRI}(1 \mathrm{H}, 7 \mathrm{~T})\end{array}$ & $\begin{array}{l}\text { Metabolic (MRS) and } \\
\text { diffusion (MRI) } \\
\text { response to hypoxia } \\
\text { and recovery }\end{array}$ & PRESS, 2pt diffusion & $\begin{array}{l}\text { Single voxel (MRS), 2D } \\
\text { (MRI) }\end{array}$ & $\begin{array}{l}6 \times 6 \times 6 \mathrm{~mm}^{3}(\mathrm{MRS}) \\
230 \times 460 \times 2000 \\
\mu \mathrm{m}^{3}(\mathrm{MRl})\end{array}$ & Ketamine & 19 & $\begin{array}{l}21.3 \mathrm{~min}(\mathrm{MRS}) \text {, not } \\
\text { reported (MRI) }\end{array}$ \\
\hline Falen et al. [53] & $\operatorname{MRI}(1 \mathrm{H}, 2 \mathrm{~T})$ & Yolk structure & SE & $2 \mathrm{D}$ & $\begin{array}{l}250 \times 250 \times 1250 \\
\mu m^{3} \text { to } 500 \times 500 \times \\
1250 \mu m^{3}\end{array}$ & Not reported & daily & $1 \mathrm{~h}$ \\
\hline $\begin{array}{l}\text { Hutchison et al. } \\
{[87]}\end{array}$ & $\operatorname{MRI}(1 \mathrm{H}, 2 \mathrm{~T})$ & Yolk structure & T1-/T2-weighted SE & $2 \mathrm{D}$ & $235 \times 310 \mu \mathrm{m}^{2}$ & Not reported & 1 & Not reported \\
\hline $\begin{array}{l}\text { Donoghue et al. } \\
\text { [88] }\end{array}$ & $\begin{array}{l}\mathrm{MRI}(1 \mathrm{H}, \\
1.5 \mathrm{~T})\end{array}$ & Residue transfer & IR-FLASH (MP-RAGE) & $3 D$ & $\begin{array}{l}1000 \times 780 \times 1250 \\
\mu \mathrm{m}^{3}\end{array}$ & Precooling & not reported & Not reported \\
\hline Holmes et al. [93] & MRI (1H, 7T) & Cardiac function & T1-weighted GE & $2 \mathrm{D}$ & $\begin{array}{l}300 \times 300 \times 1500 \\
\mu m^{3}\end{array}$ & Self-gated & $8,13,16,20$ & Not reported \\
\hline Bain et al. [51] & $\operatorname{MRI}(1 \mathrm{H}, 7 \mathrm{~T})$ & $\begin{array}{l}\text { Chick embryo } \\
\text { development }\end{array}$ & T2-weighted SE & $2 \mathrm{D}$ & $192 \times 195 \times 500 \mu \mathrm{m}^{3}$ & Precooling & $12,15,17,18,19,20$ & $25 \mathrm{~min}$ \\
\hline Boss et al. [50] & $\operatorname{MRI}(1 \mathrm{H}, 7 \mathrm{~T})$ & $\begin{array}{l}\text { MR relaxation } \\
\text { parameter changes } \\
\text { during embryonic } \\
\text { development }\end{array}$ & $\begin{array}{l}\text { IR-TSE (T1-mapping), } \\
\text { HASTE (T2-mapping), } \\
\text { MT- prepared GE }\end{array}$ & $\begin{array}{l}\text { 2D (T1/T2- mapping), } \\
\text { 3D (MTR) }\end{array}$ & $\begin{array}{l}180 \times 180 \times 1000 \\
\mu \mathrm{m}^{3}(\text { T1-mapping }) \\
260 \times 260 \times 1000 \\
\mu \mathrm{m}^{3}(\mathrm{HAST}), 230 \times \\
230 \times 1000 \mu \mathrm{m}^{3} \\
(\text { MTR) }\end{array}$ & Ketamine & $5,8,11,16$ & Not reported \\
\hline Zhou et al. [111] & $\operatorname{MRI}(1 \mathrm{H}, 3 \mathrm{~T})$ & $\begin{array}{l}\text { Muscle fiber tracking } \\
\text { during embryonic } \\
\text { development }\end{array}$ & $\begin{array}{l}\text { T1- / T2- weighted } \\
\text { TSE, DTI }\end{array}$ & $2 \mathrm{D}$ & $\begin{array}{l}200 \times 200 \times 2000 \\
\mu \mathrm{m}^{3}(\mathrm{~T} 1 \mathrm{w}), 200 \times 200 \\
\times 1200 \mu \mathrm{m}^{3}(\mathrm{~T} 2 \mathrm{w}) \\
600 \times 600 \times 1200 \\
\mu \mathrm{m}^{3}(\mathrm{dti})\end{array}$ & $\begin{array}{l}\text { No, single- and } \\
\text { double-precooling }\end{array}$ & $\begin{array}{l}4,5,6,7,8,9,10,11 \\
12,13,18,19\end{array}$ & $\begin{array}{l}2 \min 17 \mathrm{~s}(T 1 \mathrm{w}) \\
12 \min 23 \mathrm{~s}(\mathrm{t} 2 \mathrm{w}) \\
31 \min 14 \mathrm{~s}(\mathrm{DTI})\end{array}$ \\
\hline Lindner et al. [48] & MRI (1H, 7T) & $\begin{array}{l}\text { Embryonic } \\
\text { development of the eye }\end{array}$ & T2-weighted TSE & $2 \mathrm{D}$ & $74 \times 74 \times 700 \mu \mathrm{m}^{3}$ & $\begin{array}{l}\text { Bedding on crushed } \\
\text { ice for EDD }>10\end{array}$ & 1-20 daily & \\
\hline $\begin{array}{l}\text { Dingman et al. } \\
\text { [112] }\end{array}$ & $\begin{array}{l}\text { MRI (19F, not } \\
\text { reported) }\end{array}$ & $\begin{array}{l}\text { Biodistribution of } \\
\text { 19F-labeled compound }\end{array}$ & Not-reported & Not-reported & Not-reported & Not-reported & $15,16,17,18$ & \\
\hline Oppitz et al. [98] & MRI $(1 \mathrm{H}, 3 \mathrm{~T})$ & $\begin{array}{l}\text { Migration of iron } \\
\text { labeled melanoma cells }\end{array}$ & $\mathrm{T}^{*}$-weighted & $3 D$ & $300^{3}-1000^{3} \mu \mathrm{m}^{3}$ & Not reported & $6,9,18,20$ & $12 \mathrm{~s} /$ slice \\
\hline
\end{tabular}


TABLE 1 | Continued

\begin{tabular}{|c|c|c|c|c|c|c|c|c|}
\hline References & Modality & Application & Imaging technique & Dimension & Spatial resolution & Immobilization & EDD & Scan time \\
\hline $\begin{array}{l}\text { Faucher et al. } \\
{[100]}\end{array}$ & $\begin{array}{l}\mathrm{MRI}(1 \mathrm{H}, \\
1.5 \mathrm{~T})\end{array}$ & $\begin{array}{l}\text { Localization of } \\
\text { Gd-labeled GL-261 } \\
\text { glioblastoma cells }\end{array}$ & T1-weighted GR & $3 \mathrm{D}$ & $350 \times 350 \times 500 \mu \mathrm{m}^{3}$ & Precooling & $10,11,13$ & $6-7 \mathrm{~min}$ \\
\hline Zuo et al. [61] & $\begin{array}{l}\mathrm{MRI}(1 \mathrm{H}, \\
11.7 \mathrm{~T})\end{array}$ & $\begin{array}{l}\text { CAM tumor } \\
\text { morphology }\end{array}$ & $\begin{array}{l}\text { T2-weighted TSE, T2 } \\
\text { mapping, diffusion } \\
\text { weighted, T1-weighted } \\
\text { GE }\end{array}$ & $\begin{array}{l}\text { 2D (T2, T2-mapping, } \\
\text { DWI) 3D (T1 weighted } \\
\text { GE) }\end{array}$ & $\begin{array}{l}77 \times 91 \times 500 \mu \mathrm{m}^{3} \\
(\mathrm{t} 2 \mathrm{~W}), 200 \times 200 \times \\
500 \mu \mathrm{m}^{3}(\mathrm{DWl}), 104 \times \\
98 \times 500 \mu \mathrm{m}^{3}(\mathrm{~T} 2 \\
\text { mapping), } 100 \times 100 \\
\times 560 \mu \mathrm{m}^{3}\end{array}$ & Precooling & 11-16, daily & $\begin{array}{l}15 \min 32 \mathrm{~s}(\mathrm{t} 2 \mathrm{w}), \\
60 \mathrm{~min}(\mathrm{DWI}), 34 \mathrm{~min} \\
(\mathrm{~T} 2 \mathrm{mapping}), 4 \mathrm{~min} 9 \mathrm{~s} \\
(\mathrm{t} 1 \mathrm{w})\end{array}$ \\
\hline Zuo et al. [65] & $\begin{array}{l}\mathrm{MRI}(1 \mathrm{H}, \\
11.7 \mathrm{~T})\end{array}$ & $\begin{array}{l}\text { Biodistribution of } \\
\text { Gd-labeled } \\
\text { compounds }\end{array}$ & $\begin{array}{l}\text { T1-weighted GE, } \\
\text { T2-weighted SE }\end{array}$ & 3D (T1w), 2D (T1w) & $\begin{array}{l}100 \times 100 \times 560 \mu \mathrm{m} \\
(\mathrm{T} 1 \mathrm{w}), 77 \times 91 \times 500 \\
\mu \mathrm{m}^{3}(\mathrm{t} 2 \mathrm{w})\end{array}$ & Precooling & $\begin{array}{l}16 \text { (injection), pre- and } \\
30 \text { min, } 3 \mathrm{~h}, 20 \mathrm{~h}, 40 \mathrm{~h} \\
\text { after injection }\end{array}$ & $\begin{array}{l}4 \min 9 \mathrm{~s}(T 1 w), 15 \mathrm{~min} \\
32 \mathrm{~s}(\mathrm{t} 2 \mathrm{w})\end{array}$ \\
\hline Pfiffner et al. [105] & $\begin{array}{l}\mathrm{MRI}(1 \mathrm{H} \\
4.7 \mathrm{~T})\end{array}$ & $\begin{array}{l}\text { Perfusion capacity of } \\
\text { 3D biomaterials }\end{array}$ & $\begin{array}{l}\text { T1-weighted GE, T1-/ } \\
\text { T2-mapping }\end{array}$ & $2 \mathrm{D}$ & $\begin{array}{l}500 \times 500 \times 1000 \\
\mu m^{3}\end{array}$ & Ketamine & 14 & $\begin{array}{l}25 \mathrm{~s} \text { (GE), } 9 \mathrm{~min} 40 \mathrm{~s} \\
\text { (mapping) }\end{array}$ \\
\hline $\begin{array}{l}\text { Waschkies et al. } \\
\text { [106] }\end{array}$ & $\begin{array}{l}\text { see Pfiffner } \\
\text { et al. [105] }\end{array}$ & See Pfiffner et al. [105] & See Pfiffner et al. [105] & See Pfiffner et al. [105] & See Pfiffner et al. [105] & $\begin{array}{l}\text { Metetomidone, } \\
\text { thiopental, } \\
\text { ketamine/midazolam }\end{array}$ & see Pfiffner et al. [105] & See Pfiffner et al. [105] \\
\hline $\begin{array}{l}\text { Herrmann et al. } \\
\text { [58] }\end{array}$ & $\operatorname{MRI}(1 \mathrm{H}, 9.4 \mathrm{~T})$ & $\begin{array}{l}\text { Tracking of magnetic } \\
\text { particle labeled tumor } \\
\text { cells }\end{array}$ & $\begin{array}{l}\text { T2-weighted TSE, } \\
\text { T2*-weighted GE, Time } \\
\text { of flight (TOF) }\end{array}$ & $2 \mathrm{D}$ & $\begin{array}{l}88 / 166 \times 88 / 166 \times \\
400 / 500 \mathrm{~mm} 3(\mathrm{t} 2 \mathrm{~W}), 88 \\
\times 88 \times 400 \mu \mathrm{m}^{3}\left(\mathrm{t}^{*}\right. \\
\text { tof }\end{array}$ & $\begin{array}{l}\text { Precooling (T2-/T2* } \mathrm{W} \text { ), } \\
\text { ketamine (Tof) }\end{array}$ & 14 & $\begin{array}{l}13 \mathrm{~min} 24 \mathrm{~s}-31 \mathrm{~min} \\
56 \mathrm{~s}(\mathrm{t} 2 \mathrm{w}), 22 \mathrm{~min} 35 \mathrm{~s} \\
\left(\mathrm{~T} 2^{*}\right), 12 \mathrm{~min} 4 \mathrm{~s} \text { (Tof) }\end{array}$ \\
\hline Würbach et al. [71] & PET $\left({ }^{18} \mathrm{~F}\right)$ & Bone metabolism & Static, dynamic & $3 \mathrm{D}$ & $400 \times 400 \times 800 \mu \mathrm{m}^{3}$ & Isoflurane & $13-18$ & $75 \mathrm{~min}$ \\
\hline $\begin{array}{l}\text { Heidrich et al. } \\
\text { [107] }\end{array}$ & $\mathrm{PET} / \mu \mathrm{CT}$ & Immobilization & Static & 3D & Not reported & $\begin{array}{l}\text { Isoflurane, } \\
\text { 2,2,2-tribromoethanol, } \\
\text { urethane/ } \alpha \text {-chloralose }\end{array}$ & $11-18$ & $6 \mathrm{~min}$ \\
\hline Warnock et al. [69] & $\begin{array}{l}\mathrm{PET}\left({ }^{18} \mathrm{~F}\right) / \\
\mu \mathrm{CT}\end{array}$ & $\begin{array}{l}\text { Screening of novel PET } \\
\text { tracer }\end{array}$ & Dynamic, static & $3 \mathrm{D}$ & $\begin{array}{l}433 \times 433 \times 796 \mu \mathrm{m}^{3} \\
(\mathrm{PET}), 100^{3} \mu \mathrm{m}^{3}(\mu \mathrm{ct})\end{array}$ & Isoflurane & 18 & $\begin{array}{l}45 \text { min (PET), } \\
\text { not-reported ( } \mu \mathrm{ct})\end{array}$ \\
\hline $\begin{array}{l}\text { Zlatopolskiy et al. } \\
\text { [68] }\end{array}$ & PET $\left({ }^{18} \mathrm{~F}\right)$ & $\begin{array}{l}\text { Tracer accumulation in } \\
\text { CAM tumor }\end{array}$ & Static & $3 \mathrm{D}$ & $1.4^{3} \mathrm{~mm}^{3}(\mathrm{PET})$ & Isoflurane & 7 & $30 \mathrm{~min}$ \\
\hline $\begin{array}{l}\text { Steinemann et al. } \\
\text { [109] }\end{array}$ & $\begin{array}{l}\operatorname{PET}\left({ }^{18} \mathrm{~F}\right) / \\
\operatorname{MRI}(1 \mathrm{H}, 1 \mathrm{~T})\end{array}$ & $\begin{array}{l}\text { Tumor growth and } \\
\text { metabolism }\end{array}$ & $\begin{array}{l}\text { T1-weighted GE, } \\
\text { T2-weighted TSE, } \\
\text { static (PET) }\end{array}$ & 3D (GE, PET), 2D (TSE) & $\begin{array}{l}290 \times 290 \times 500 \mu \mathrm{m}^{3} \\
\text { (GE), } 290 \times 290 \times 700 \\
\mu \mathrm{m}^{3} \text { (TSE), not } \\
\text { reported (PET) }\end{array}$ & Precooling & 10,17 & Not reported \\
\hline Winter et al. [110] & $\begin{array}{l}\left.\text { PET ( }{ }^{8} \mathrm{Ga}\right), \\
\mathrm{MRI}(1 \mathrm{H}, \\
11.7 \mathrm{~T})\end{array}$ & $\begin{array}{l}\text { Binding specificity of } \\
\text { target-specific } \\
\text { radioligands }\end{array}$ & $\begin{array}{l}\text { Dynamic (PET), } \\
\text { T2-/T1-weighted SE } \\
\text { (MRI) }\end{array}$ & 3D (PET), 2D (MRI) & $\begin{array}{l}1.4^{3} \mathrm{~mm}^{3}(\mathrm{PET}), 100 \times \\
100 \times 560 \mu \mathrm{m}(\mathrm{T} 1 \mathrm{w}) \\
77 \times 91 \times 500 \mu \mathrm{m}^{3} \\
(\mathrm{t} 2 \mathrm{w})\end{array}$ & $\begin{array}{l}\text { Precooling (MRI), none } \\
\text { (PET) }\end{array}$ & 12 & \\
\hline
\end{tabular}

MRI, magnetic resonance imaging; MRS, magnetic resonance spectroscopy; PET, positron emission tomography; $\mu C T$, microscopy computer tomography; SE, spin echo; TSE, turbo spin echo; GE, gradient echo; IR, inversion recovery; MT, magnetization transfer; FLASH, fast low angle shot; HASTE, half-Fourier single-shot turbo spin echo. 
optical methods [116, 117] including bioluminescence [118], fluorescence [119], and tomographic [120, 121] techniques. Furthermore, ultrasonographic imaging [122], x-ray based tomographic [45] and even photoacoustic techniques [123] have been introduced, the latter of which with the potential for label-free imaging. In combination with single photon emission tomography (SPECT), tomographic $\mathrm{x}$-ray techniques have been applied to initial evaluation of radiopharmaceuticals in chick embryos [19].

In conclusion, the expected increasing interest in the HETCAM model as an intermediate step between cell culture and animal model for initial testing of new compounds makes in ovo imaging an important tool for monitoring the fate of compounds after systemic injection or surrogate markers. The combination of MRI and PET appears promising by combining the sensitivity of PET with detailed anatomic and functional information provided by MRI.

\section{REFERENCES}

1. Ribatti D. The chick embryo chorioallantoic membrane (CAM). A multifaceted experimental model. Mech Dev. (2016) 141:707. doi: 10.1016/j.mod.2016.05.003

2. Buchele B, Zugmaier W, Genze F, Simmet T. High-performance liquid chromatographic determination of acetyl-11-keto-alpha-boswellic acid, a novel pentacyclic triterpenoid, in plasma using a fluorinated stationary phase and photodiode array detection: application in pharmacokinetic studies. J Chromatogr B Analyt Technol Biomed Life Sci. (2005) 829:1448. doi: 10.1016/j.jchromb.2005.09.043

3. Syrovets T, Gschwend JE, Buchele B, Laumonnier Y, Zugmaier W, Genze F, et al. Inhibition of IkappaB kinase activity by acetyl-boswellic acids promotes apoptosis in androgen-independent $\mathrm{PC}-3$ prostate cancer cells in vitro and in vivo. J Biol Chem. (2005) 280:6170-80. doi: 10.1074/jbc.M409477200

4. Estrada AC, Syrovets T, Pitterle K, Lunov O, Buchele B, Schimana-Pfeifer J, et al. Tirucallic acids are novel pleckstrin homology domain-dependent Akt inhibitors inducing apoptosis in prostate cancer cells. Mol Pharmacol. (2010) 77:378-87. doi: 10.1124/mol.109.060475

5. Morad SA, Schmidt C, Buchele B, Schneider B, Wenzler M, Syrovets T, et al. (8R)-3beta,8-dihydroxypolypoda-13E,17E,21-triene induces cell cycle arrest and apoptosis in treatment-resistant prostate cancer cells. J Nat Prod. (2011) 74:1731-6. doi: 10.1021/np200161a

6. Morad SA, Schmid M, Buchele B, Siehl HU, El Gafaary M, Lunov $\mathrm{O}$, et al. A novel semisynthetic inhibitor of the FRB domain of mammalian target of rapamycin blocks proliferation and triggers apoptosis in chemoresistant prostate cancer cells. Mol Pharmacol. (2013) 83:53141. doi: $10.1124 / \mathrm{mol} .112 .081349$

7. Vogler M, Walczak H, Stadel D, Haas TL, Genze F, Jovanovic M, et al. Targeting XIAP bypasses Bcl-2-mediated resistance to TRAIL and cooperates with TRAIL to suppress pancreatic cancer growth in vitro and in vivo. Cancer Res. (2008) 68:7956-65. doi: 10.1158/0008-5472.CAN-08-1296

8. Swadi RR, Sampat K, Herrmann A, Losty PD, See V, Moss DJ. CDK inhibitors reduce cell proliferation and reverse hypoxia-induced metastasis of neuroblastoma tumours in a chick embryo model. Sci Rep. (2019) 9:9136. doi: 10.1038/s41598-019-45571-8

9. Loos C, Syrovets T, Musyanovych A, Mailander V, Landfester K, Simmet T. Amino-functionalized nanoparticles as inhibitors of mTOR and inducers of cell cycle arrest in leukemia cells. Biomaterials. (2014) 35:194453. doi: 10.1016/j.biomaterials.2013.11.056

10. Vargas A, Zeisser-Labouebe M, Lange N, Gurny R, Delie F. The chick embryo and its chorioallantoic membrane (CAM) for the in vivo evaluation of drug delivery systems. Adv Drug Deliv Rev. (2007) 59:116276. doi: $10.1016 /$ j.addr.2007.04.019

\section{AUTHOR CONTRIBUTIONS}

$\mathrm{GW}, \mathrm{AK}, \mathrm{JL}, \mathrm{AA}, \mathrm{AB}, \mathrm{HL}$, and $\mathrm{ZZ}$ performed measurements in the context of the presented work. FJ and ML provided in-depth knowledge on nano-particles. GW and VR wrote the manuscript, and are responsible for the in ovo experiments.

\section{ACKNOWLEDGMENTS}

The authors received funding from the European Union's Horizon 2020 research and innovation programme under grant agreement No. 667192, and by the Deutsche Forschungsgemeinschaft (DFG) through the Collaborative Research Center 1279-The exploration of the Human Peptidome. Further the general support of the MoMAN imaging center of Ulm University is acknowledged.

11. Lunov O, Syrovets T, Loos C, Beil J, Delacher M, Tron K, et al. Differential uptake of functionalized polystyrene nanoparticles by human macrophages and a monocytic cell line. ACS Nano. (2011) 5:165769. doi: $10.1021 / \mathrm{nn} 2000756$

12. Leng T, Miller JM, Bilbao KV, Palanker DV, Huie P, Blumenkranz MS. The chick chorioallantoic membrane as a model tissue for surgical retinal research and simulation. Retina. (2004) 24:427-34. doi: 10.1097/00006982-200406000-00014

13. DeBord LC, Pathak RR, Villaneuva M, Liu HC, Harrington DA, Yu W, et al. The chick chorioallantoic membrane (CAM) as a versatile patient-derived xenograft (PDX) platform for precision medicine and preclinical research. Am J Cancer Res. (2018) 8:1642-60.

14. Vu BT, Shahin SA, Croissant J, Fatieiev Y, Matsumoto K, Le-Hoang Doan $\mathrm{T}$, et al. Chick chorioallantoic membrane assay as an in vivo model to study the effect of nanoparticle-based anticancer drugs in ovarian cancer. Sci Rep. (2018) 8:8524. doi: 10.1038/s41598-018-25573-8

15. Ribatti D, Tamma R. The chick embryo chorioallantoic membrane as an in vivo experimental model to study human neuroblastoma. J Cell Physiol. (2018) 234:152-7. doi: 10.1002/jcp.26773

16. Ribatti $\mathrm{D}$. The chick embryo chorioallantoic membrane as a model for tumor biology. Exp Cell Res. (2014) 328:314-24. doi: 10.1016/j.yexcr.2014.06.010

17. Gabrielli MG, Accili D. The chick chorioallantoic membrane: a model of molecular, structural, and functional adaptation to transepithelial ion transport and barrier function during embryonic development. J Biomed Biotechnol. (2010) 2010:940741. doi: 10.1155/2010/940741

18. Nowak-Sliwinska P, Segura T, Iruela-Arispe ML. The chicken chorioallantoic membrane model in biology, medicine and bioengineering. Angiogenesis. (2014) 17:779-804. doi: 10.1007/s10456-014-9440-7

19. Haller S, Ametamey SM, Schibli R, Muller C. Investigation of the chick embryo as a potential alternative to the mouse for evaluation of radiopharmaceuticals. Nucl Med Biol. (2015) 42:226-33. doi: 10.1016/j.nucmedbio.2014.10.010

20. Duman R, Ertekin T, Duman R, Aslan E, Sabaner MC, Cetinkaya E. The novel model: Experimental optical coherence tomography-guided anterior segment imaging chick embryo model. Indian J Ophthalmol. (2019) 67:548. doi: 10.4103/ijo.IJO_263_18

21. Ko ZY, Mehta K, Jamil M, Yap CH, Chen N. A method to study the hemodynamics of chicken embryo's aortic arches using optical coherence tomography. J Biophotonics. (2017) 10:353-9. doi: 10.1002/jbio.2016 00119

22. Goenezen S, Chivukula VK, Midgett M, Phan L, Rugonyi S. 4D subject-specific inverse modeling of the chick embryonic heart outflow tract hemodynamics. Biomech Model Mechanobiol. (2016) 15:723-43. doi: 10.1007/s10237-015-0720-y 
23. Midgett M, Chivukula VK, Dorn C, Wallace S, Rugonyi S. Blood flow through the embryonic heart outflow tract during cardiac looping in HH13-HH18 chicken embryos. J R Soc Interface. (2015) 12:20150652. doi: 10.1098/rsif.2015.0652

24. Ma Z, Dou S, Zhao Y, Guo C, Liu J, Wang Q, et al. In vivo assessment of wall strain in embryonic chick heart by spectral domain optical coherence tomography. Appl Opt. (2015) 54:9253-7. doi: 10.1364/AO.54.009253

25. Filas BA, Xu G, Taber LA. Probing regional mechanical properties of embryonic tissue using microindentation and optical coherence tomography. Methods Mol Biol. (2015) 1189:3-16. doi: 10.1007/978-1-4939-1164-6_1

26. Yin X, Liu A, Thornburg KL, Wang RK, Rugonyi S. Extracting cardiac shapes and motion of the chick embryo heart outflow tract from fourdimensional optical coherence tomography images. J Biomed Opt. (2012) 17:96005-1. doi: 10.1117/1.JBO.17.9.096005

27. Liu A, Yin X, Shi L, Li P, Thornburg KL, Wang R, et al. Biomechanics of the chick embryonic heart outflow tract at $\mathrm{HH} 18$ using $4 \mathrm{D}$ optical coherence tomography imaging and computational modeling. PLoS ONE. (2012) 7:e40869. doi: 10.1371/journal.pone.0040869

28. Li P, Wang RK. Optical coherence tomography provides an ability to assess mechanical property of cardiac wall of developing outflow tract in embryonic heart in vivo. J Biomed Opt. (2012) 17:120502. doi: 10.1117/1.JBO.17.12.120502

29. Li P, Yin X, Shi L, Rugonyi S, Wang RK. In vivo functional imaging of blood flow and wall strain rate in outflow tract of embryonic chick heart using ultrafast spectral domain optical coherence tomography. J Biomed Opt. (2012) 17:96006-1. doi: 10.1117/1.JBO.17.9.096006

30. Happel CM, Thommes J, Thrane L, Manner J, Ortmaier T, Heimann B, et al. Rotationally acquired four-dimensional optical coherence tomography of embryonic chick hearts using retrospective gating on the common central A-scan. J Biomed Opt. (2011) 16:096007. doi: 10.1117/1.3622491

31. Liu X, Zhang K, Huang Y, Kang JU. Spectroscopic-speckle variance OCT for microvasculature detection and analysis. Biomed Opt Express. (2011) 2:2995-3009. doi: 10.1364/BOE.2.002995

32. Li P, Yin X, Shi L, Liu A, Rugonyi S, Wang R. Measurement of strain and strain rate in embryonic chick heart in vivo using spectral domain optical coherence tomography. IEEE Trans Biomed Eng. (2011) 58:51. doi: 10.1109/TBME.2011.2153851

33. Osiac E, Saftoiu A, Gheonea DI, Mandrila I, Angelescu R. Optical coherence tomography and Doppler optical coherence tomography in the gastrointestinal tract. World J Gastroenterol. (2011) 17:1520. doi: 10.3748/wjg.v17.i1.15

34. Manner J, Thrane L, Norozi K, Yelbuz TM. In vivo imaging of the cyclic changes in cross-sectional shape of the ventricular segment of pulsating embryonic chick hearts at stages 14 to 17: a contribution to the understanding of the ontogenesis of cardiac pumping function. Dev Dyn. (2009) 238:3273-84. doi: 10.1002/dvdy.22159

35. Liu A, Wang R, Thornburg KL, Rugonyi S. Efficient postacquisition synchronization of 4-D nongated cardiac images obtained from optical coherence tomography: application to 4-D reconstruction of the chick embryonic heart. J Biomed Opt. (2009) 14:044020. doi: 10.1117/1.3184462

36. Rugonyi S, Shaut C, Liu A, Thornburg K, Wang RK. Changes in wall motion and blood flow in the outflow tract of chick embryonic hearts observed with optical coherence tomography after outflow tract banding and vitelline-vein ligation. Phys Med Biol. (2008) 53:507791. doi: 10.1088/0031-9155/53/18/015

37. Filas BA, Knutsen AK, Bayly PV, Taber LA. A new method for measuring deformation of folding surfaces during morphogenesis. J Biomech Eng. (2008) 130:061010. doi: 10.1115/1.2979866

38. Chen Z, Milner TE, Srinivas S, Wang X, Malekafzali A, van Gemert MJ, et al. Noninvasive imaging of in vivo blood flow velocity using optical Doppler tomography. Opt Lett. (1997) 22:1119-21. doi: 10.1364/OL.22.001119

39. Seal HE, Lilian SJ, Popratiloff A, Hirsch JC, Peusner KD. Implementing the chick embryo model to study vestibular developmental disorders. $J$ Neurophysiol. (2019) 122:2272-83. doi: 10.1152/jn.00434.2019

40. Shigeta Y, Fujiwara N, Koike M, Yamataka A, Doi T. Bone mineral density is increased in the cadmium-induced omphalocele chick model by using three-dimensional micro-computed tomography. Pediatr Surg Int. (2019) 35:911-4. doi: 10.1007/s00383-019-04501-5

41. Moreno-Jimenez I, Hulsart-Billstrom G, Lanham SA, Janeczek AA, Kontouli N, Kanczler JM, et al. The chorioallantoic membrane (CAM) assay for the study of human bone regeneration: a refinement animal model for tissue engineering. Sci Rep. (2016) 6:32168. doi: 10.1038/srep32168

42. Yair R, Shahar R, Uni Z. In ovo feeding with minerals and vitamin D3 improves bone properties in hatchlings and mature broilers. Poult Sci. (2015) 94:2695-707. doi: 10.3382/ps/pev252

43. Milisits G, Donko T, Dalle Zotte A, Sartori A, Szentirmai E, Emri M, et al. Application of computed tomography to assess the effect of egg yolk ratio on body composition in chickens of different genotype and gender at hatch and during the rearing period. Br Poult Sci. (2013) 54:6119. doi: 10.1080/00071668.2013.811714

44. Henning AL, Jiang MX, Yalcin HC, Butcher JT. Quantitative three-dimensional imaging of live avian embryonic morphogenesis via micro-computed tomography. Dev Dyn. (2011) 240:194957. doi: $10.1002 /$ dvdy.22694

45. Kim JS, Min J, Recknagel AK, Riccio M, Butcher JT. Quantitative threedimensional analysis of embryonic chick morphogenesis via microcomputed tomography. Anat Rec (Hoboken). (2011) :1-10. doi: 10.1002/ar.21276

46. Metscher BD. MicroCT for developmental biology: a versatile tool for highcontrast 3D imaging at histological resolutions. Dev Dyn. (2009) 238:63240. doi: 10.1002/dvdy.21857

47. Chevalier NR, Dacher N, Jacques C, Langlois L, Guedj C, Faklaris O. Embryogenesis of the peristaltic reflex. J Physiol. (2019) 597:2785801. doi: 10.1113/JP277746

48. Lindner T, Klose R, Streckenbach F, Stahnke T, Hadlich S, Kuhn JP, et al. Morphologic and biometric evaluation of chick embryo eyes in ovo using 7 Tesla MRI. Sci Rep. (2017) 7:2647. doi: 10.1038/s41598-017-02755-4

49. Zhou Z, Chen Z, Shan J, Ma W, Li L, Zu J, et al. Monitoring brain development of chick embryos in vivo using 3.0 T MRI: subdivision volume change and preliminary structural quantification using DTI. BMC Dev Biol. (2015) 15:29. doi: 10.1186/s12861-015-0077-6

50. Boss A, Oppitz M, Wehrl HF, Rossi C, Feuerstein M, Claussen CD, et al. Measurement of T1, T2, and magnetization transfer properties during embryonic development at 7 Tesla using the chicken model. J Magn Reson Imaging. (2008) 28:1510-4. doi: 10.1002/jmri.21601

51. Bain MM, Fagan AJ, Mullin JM, McNaught I, McLean J, Condon B. Noninvasive monitoring of chick development in ovo using a 7T MRI system from day 12 of incubation through to hatching. J Magn Reson Imaging. (2007) 26:198-201. doi: 10.1002/jmri.20963

52. Hogers B, Gross D, Lehmann V, de Groot HJ, de Roos A, Gittenbergerde Groot AC, et al. Magnetic resonance microscopy at 17.6-Tesla on chicken embryos in vitro. J Magn Reson Imaging. (2001) 14:836. doi: 10.1002/jmri.1155

53. Falen SW, Szeverenyi NM, Packard DS, Jr., Ruocco MJ. Magnetic resonance imaging study of the structure of the yolk in the developing avian egg. $J$ Morphol. (1991) 209:331-42. doi: 10.1002/jmor.1052090308

54. Moseley ME, Wendland MF, Darnell DK, Gooding CA. Metabolic and anatomic development of the chick embryo as studied by phosphorus-31 magnetic resonance spectroscopy and proton MRI. Pediatr Radiol. (1989) 19:400-5. doi: 10.1007/BF02387637

55. Streckenbach F, Klose R, Langner S, Langner I, Frank M, Wree A, et al. Ultrahigh-field quantitative $\mathrm{mr}$ microscopy of the chicken eye in vivo throughout the in ovo period. Mol Imaging Biol. (2019) 21:7885. doi: 10.1007/s11307-018-1208-9

56. Klose R, Streckenbach F, Hadlich S, Stahnke T, Guthoff R, Wree A, et al. [Ultra-high-field MRI in the Chicken Embryo in Ovo - a Model for Experimental Ophthalmology]. Klin Monbl Augenheilkd. (2017) 234:145862. doi: $10.1055 / \mathrm{s}-0043-120675$

57. Goodall N, Kisiswa L, Prashar A, Faulkner S, Tokarczuk P, Singh K, et al. 3-Dimensional modelling of chick embryo eye development and growth using high resolution magnetic resonance imaging. Exp Eye Res. (2009) 89:511-21. doi: 10.1016/j.exer.2009.05.014

58. Herrmann A, Taylor A, Murray P, Poptani H, See V. Magnetic resonance imaging for characterization of a chick 
embryo model of cancer cell metastases. Mol Imaging.

(2018) 17:1536012118809585. doi: 10.1177/1536012118809585

59. Shrivastava S, Barmon D, Kataki AC, Deka P, Sharma JD, Choudhary BK, et al. Magnetic resonance imaging in pre-operative staging of endometrial cancer. Indian J Cancer. (2016) 53:181-5. doi: 10.4103/0019-509X.180859

60. Tung YT, Huang PW, Chou YC, Lai CW, Wang HP, Ho HC, et al. Lung tumorigenesis induced by human vascular endothelial growth factor (hVEGF)-A165 overexpression in transgenic mice and amelioration of tumor formation by miR-16. Oncotarget. (2015) 6:1022238. doi: 10.18632/oncotarget.3390

61. Zuo Z, Syrovets T, Genze F, Abaei A, Ma G, Simmet T, et al. High-resolution MRI analysis of breast cancer xenograft on the chick chorioallantoic membrane. NMR Biomed. (2015) 28:440-7. doi: 10.1002/nbm.3270

62. Al-Mutawa YK, Herrmann A, Corbishley C, Losty PD, Phelan M, See V. Effects of hypoxic preconditioning on neuroblastoma tumour oxygenation and metabolic signature in a chick embryo model. Biosci Rep. (2018) 38:185. doi: 10.1042/BSR20180185

63. Herrmann A, Rice M, Levy R, Pizer BL, Losty PD, Moss D, et al. Cellular memory of hypoxia elicits neuroblastoma metastasis and enables invasion by non-aggressive neighbouring cells. Oncogenesis. (2015) 4:e138. doi: 10.1038/oncsis.2014.52

64. Kumar V, Nag TC, Sharma U, Mewar S, Jagannathan NR, Wadhwa S. High resolution $1 \mathrm{H}$ NMR-based metabonomic study of the auditory cortex analogue of developing chick (Gallus gallus domesticus) following prenatal chronic loud music and noise exposure. Neurochem Int. (2014) 76:99108. doi: 10.1016/j.neuint.2014.07.002

65. Zuo Z, Syrovets T, Wu Y, Hafner S, Vernikouskaya I, Liu W, et al. The CAM cancer xenograft as a model for initial evaluation of MR labelled compounds. Sci Rep. (2017) 7:46690. doi: 10.1038/srep46690

66. Goodfellow F, Simchick GA, Mortensen LJ, Stice SL, Zhao Q. Tracking and quantification of magnetically labeled stem cells using magnetic resonance imaging. Adv Funct Mater. (2016) 26:3899-915. doi: 10.1002/adfm.201504444

67. Pereira SM, Herrmann A, Moss D, Poptani H, Williams SR, Murray P, et al. Evaluating the effectiveness of transferrin receptor-1 (TfR1) as a magnetic resonance reporter gene. Contrast Media Mol Imaging. (2016) 11:236-44. doi: 10.1002/cmmi.1686

68. Zlatopolskiy BD, Zischler J, Schafer D, Urusova EA, Guliyev M, Bannykh O, et al. Discovery of 7-[(18)F]Fluorotryptophan as a novel positron emission tomography (PET) probe for the visualization of tryptophan metabolism in vivo. J Med Chem. (2018) 61:189-206. doi: 10.1021/acs.jmedchem.7b01245

69. Warnock G, Turtoi A, Blomme A, Bretin F, Bahri MA, Lemaire C, et al. In vivo PET/CT in a human glioblastoma chicken chorioallantoic membrane model: a new tool for oncology and radiotracer development. J Nucl Med. (2013) 54:1782-8. doi: 10.2967/jnumed.112.117150

70. Gebhardt P, Wurbach L, Heidrich A, Heinrich L, Walther M, Opfermann T, et al. Dynamic behaviour of selected PET tracers in embryonated chicken eggs. Rev Esp Med Nucl Imagen Mol. (2013) 32:371-7. doi: 10.1016/j.remnie.2013.09.013

71. Wurbach L, Heidrich A, Opfermann T, Gebhardt P, Saluz HP. Insights into bone metabolism of avian embryos in ovo via $3 \mathrm{D}$ and $4 \mathrm{D} 18 \mathrm{~F}$ fluoride positron emission tomography. Mol Imaging Biol. (2012) 14:68898. doi: 10.1007/s11307-012-0550-6

72. Fiebig HH, Maier A, Burger AM. Clonogenic assay with established human tumour xenografts: correlation of in vitro to in vivo activity as a basis for anticancer drug discovery. Eur J Cancer. (2004) 40:80220. doi: 10.1016/j.ejca.2004.01.009

73. Landis MD, Lehmann BD, Pietenpol JA, Chang JC. Patient-derived breast tumor xenografts facilitating personalized cancer therapy. Breast Cancer Res. (2013) 15:201. doi: 10.1186/bcr3355

74. de Bono JS, Ashworth A. Translating cancer research into targeted therapeutics. Nature. (2010) 467:543-9. doi: 10.1038/nature09339

75. Tentler JJ, Tan AC, Weekes CD, Jimeno A, Leong S, Pitts TM, et al. Patientderived tumour xenografts as models for oncology drug development. Nat Rev Clin Oncol. (2012) 9:338-50. doi: 10.1038/nrclinonc.2012.61

76. Rosfjord E, Lucas J, Li G, Gerber HP. Advances in patientderived tumor xenografts: from target identification to predicting clinical response rates in oncology. Biochem Pharmacol. (2014) 91:135-43. doi: 10.1016/j.bcp.2014.06.008

77. Galuschka C, Proynova R, Roth B, Augustin HG, MullerDecker K. Models in translational oncology: a public resource database for preclinical cancer research. Cancer Res. (2017) 77:2557-63. doi: 10.1158/0008-5472.CAN-16-3099

78. Lokman NA, Elder AS, Ricciardelli C, Oehler MK. Chick chorioallantoic membrane (CAM) assay as an in vivo model to study the effect of newly identified molecules on ovarian cancer invasion and metastasis. Int J Mol Sci. (2012) 13:9959-70. doi: 10.3390/ijms13089959

79. Ribatti D. The chick embryo chorioallantoic membrane (CAM) assay. Reprod Toxicol. (2017) 70:97-101. doi: 10.1016/j.reprotox.2016.11.004

80. Hamburger V, Hamilton HL. A series of normal stages in the development of the chick embryo. J Morphol. (1951) 88:49-92. doi: 10.1002/jmor.1050880104

81. Bone SN, Johnson GA, Thompson MB. Three-dimensional magnetic resonance microscopy of the developing chick embryo. Invest Radiol. (1986) 21:782-7. doi: 10.1097/00004424-198610000-00003

82. Johnson GA, Thompson MB, Drayer BP, Bone SN. Magnetic resonance microscopy in neurologic models. Acta Radiol Suppl. (1986) 369:267-8.

83. Effmann EL, Johnson GA, Smith BR, Talbott GA, Cofer G. Magnetic resonance microscopy of chick embryos in ovo. Teratology. (1988) 38:5965. doi: 10.1002/tera.1420380109

84. Hollett MD, Cofer GP, Johnson GA. In situ magnetic resonance microscopy. Invest Radiol. (1987) 22:965-8. doi: 10.1097/00004424-198712000-00009

85. Lirette A, Towner RA, Liu Z EG, Janzen. Chambers JR, Fairfull RW, Milligan $\mathrm{LP}$, et al. In vivo nuclear magnetic resonance spectroscopy of chicken embryos from two broiler strains of varying fat content. Poult Sci. (1993) 72:1411-20. doi: 10.3382/ps.0721411

86. Peebles DM, Dixon JC, Thornton JS, Cady EB, Priest A, Miller SL, et al. Magnetic resonance proton spectroscopy and diffusion weighted imaging of chick embryo brain in ovo. Brain Res Dev Brain Res. (2003) 141:1017. doi: 10.1016/S0165-3806(03)00002-6

87. Hutchison MJ, Lirette A, Etches RJ, Towner RA, Janzen EG. Research note: an assessment of egg yolk structure using magnetic resonance imaging. Poult Sci. (1992) 71:2117-21. doi: 10.3382/ps.0712117

88. Donoghue DJ, Myers K. Imaging residue transfer into egg yolks. J Agric Food Chem. (2000) 48:6428-30. doi: 10.1021/jf000146h

89. Smith BR, Effmann EL, Johnson GA. MR microscopy of chick embryo vasculature. J Magn Reson Imaging. (1992) 2:237-40. doi: 10.1002/jmri.1880020220

90. Zhang X, Yelbuz TM, Cofer GP, Choma MA, Kirby ML, Johnson GA. Improved preparation of chick embryonic samples for magnetic resonance microscopy. Magn Reson Med. (2003) 49:1192-5. doi: 10.1002/mrm. 10460

91. Yelbuz TM, Zhang X, Choma MA, Stadt HA, Zdanowicz M, Johnson GA, et al. Images in cardiovascular medicine. Approaching cardiac development in three dimensions by magnetic resonance microscopy. Circulation. (2003) 108:e154-5. doi: 10.1161/01.CIR.0000102940.17908.CA

92. Yelbuz TM, Waldo KL, Zhang X, Zdanowicz M, Parker J, Creazzo TL, et al. Myocardial volume and organization are changed by failure of addition of secondary heart field myocardium to the cardiac outflow tract. Dev Dyn. (2003) 228:152-60. doi: 10.1002/dvdy.10364

93. Holmes WM, McCabe C, Mullin JM, Condon B, Bain MM. Images in cardiovascular medicine. Noninvasive self-gated magnetic resonance cardiac imaging of developing chick embryos in ovo. Circulation. (2008) 117:e3467. doi: 10.1161/CIRCULATIONAHA.107.747154

94. Holmes WM, McCabe C, Mullin JM, Condon B, Bain MM. In ovo noninvasive quantification of the myocardial function and mass of chick embryos using magnetic resonance imaging. NMR Biomed. (2009) 22:74552. doi: $10.1002 / \mathrm{nbm} .1386$

95. Li X, Liu J, Davey M, Duce S, Jaberi N, Liu G, et al. Micromagnetic resonance imaging of avian embryos. J Anat. (2007) 211:798809. doi: 10.1111/j.1469-7580.2007.00825.x

96. Goodfellow FT, Tesla B, Simchick G, Zhao Q, Hodge T, Brindley MA, et al. Zika virus induced mortality and microcephaly in chicken embryos. Stem Cells Dev. (2016) 25:1691-7. doi: 10.1089/scd.2016.0231 
97. Dingman S, Hurlburt L, Thomas R, Guo C. Tissue immunoassay for 19Ftagged 5-hydroxytryptophan. J Immunoassay Immunochem. (2003) 24:32544. doi: 10.1081/IAS-120025771

98. Oppitz M, Pintaske J, Kehlbach R, Schick F, Schriek G, Busch C. Magnetic resonance imaging of iron-oxide labeled SK-Mel 28 human melanoma cells in the chick embryo using a clinical whole body MRI scanner. MAGMA. (2007) 20:1-9. doi: 10.1007/s10334-006-0062-y

99. Pereira SM, Moss D, Williams SR, Murray P, Taylor A. Overexpression of the MRI reporter genes ferritin and transferrin receptor affect iron homeostasis and produce limited contrast in mesenchymal stem cells. Int J Mol Sci. (2015) 16:15481-96. doi: 10.3390/ijms160715481

100. Faucher L, Guay-Begin AA, Lagueux J, Cote MF, Petitclerc E, Fortin MA. Ultra-small gadolinium oxide nanoparticles to image brain cancer cells in vivo with MRI. Contrast Media Mol Imaging. (2011) 6:20918. doi: $10.1002 / \mathrm{cmmi} .420$

101. Taylor A, Herrmann A, Moss D, See V, Davies K, Williams SR, et al. Assessing the efficacy of nano- and micro-sized magnetic particles as contrast agents for MRI cell tracking. PLoS ONE. (2014) 9:e100259. doi: 10.1371/journal.pone.0100259

102. Hafner S, Raabe M, Wu Y, Wang T, Zuo Z, Rasche V, et al. Highcontrast magnetic resonance imaging and efficientdelivery of an albumin nanotheranostic in triple-negativebreast cancer xenografts. Adv Therap. (2019) 2:1900084. doi: 10.1002/adtp.201900084

103. Buschmann J, Welti M, Hemmi S, Neuenschwander P, Baltes C, Giovanoli P, et al. Three-dimensional co-cultures of osteoblasts and endothelial cells in DegraPol foam: histological and high-field magnetic resonance imaging analyses of pre-engineered capillary networks in bone grafts. Tissue Eng Part A. (2011) 17:291-9. doi: 10.1089/ten.tea.201 0.0278

104. Chesnick IE, Fowler CB, Mason JT, Potter K. Novel mineral contrast agent for magnetic resonance studies of bone implants grown on a chick chorioallantoic membrane. Magn Reson Imaging. (2011) 29:124454. doi: 10.1016/j.mri.2011.07.022

105. Kivrak Pfiffner F, Waschkies C, Tian Y, Woloszyk A, Calcagni M, Giovanoli $\mathrm{P}$, et al. A new in vivo magnetic resonance imaging method to noninvasively monitor and quantify the perfusion capacity of three-dimensional biomaterials grown on the chorioallantoic membrane of chick embryos. Tissue Eng Part C Methods. (2015) 21:339-46. doi: 10.1089/ten.tec.201 4.0212

106. Waschkies C, Nicholls F, Buschmann J. Comparison of medetomidine, thiopental and ketamine/midazolam anesthesia in chick embryos for in ovo Magnetic Resonance Imaging free of motion artifacts. Sci Rep. (2015) 5:15536. doi: 10.1038/srep 15536

107. Heidrich A, Wurbach L, Opfermann T, Saluz HP. Motion-artifactfree in vivo imaging utilizing narcotized avian embryos in ovo. Mol Imaging Biol. (2011) 13:208-14. doi: 10.1007/s11307-010-0 355-4

108. Freesmeyer M, Kuehnel C, Opfermann T, Niksch T, Wiegand S, Stolz $\mathrm{R}$, et al. The use of ostrich eggs for in ovo research: making preclinical imaging research affordable and available. J Nucl Med. (2018) 59:19016. doi: 10.2967/jnumed.118.210310

109. Steinemann G, Dittmer A, Schmidt J, Josuttis D, Fahling M, Biersack B, et al. Antitumor and antiangiogenic activity of the novel chimeric inhibitor animacroxam in testicular germ cell cancer. Mol Oncol. (2019) 13:267996. doi: 10.1002/1878-0261.12582
110. Winter G, Koch A, Subgang A, Solbach C, Glatting G, Rasche V, et al. Evaluation of binding specificity of target-specific radioligands in xenografts by multi-modal PET and MR imaging using the Hen's egg test chorioallantoic membrane (HET-CAM) model. J Nucl Med. (2019) 16:1003.

111. Zhou Z, Xu J, Delproposto ZS, Hua J, Fan Y, Zhang Z, et al. Feasibility of in ovo diffusion tractography in the chick embryo using a dual-cooling technique. J Magn Reson Imaging. (2012) 36:9931001. doi: 10.1002/jmri.23684

112. Dingman S, Hurlburt L, Branch C. Acute no-effect dose for in ova exposure to C3F7 tagged 5-hydroxytryptophan, a novel probe for investigating neural development. Mol Imaging Biol. (2004) 6:126. doi: 10.1016/j.mibio.2003.11.001

113. Tazawa H, Rahn H. Temperature and metabolism of chick embryos and hatchlings after prolonged cooling. J Exp Zool Suppl. (1987) 1:105-9.

114. Wojtczak JA. The hemodynamic effects of halothane and isoflurane in chick embryo. Anesth Analg. (2000) 90:13315. doi: 10.1097/00000539-200006000-00012

115. Berry DG. Effect of ketamine on the isolated chick embryo heart. Anesth Analg. (1974) 53:919-23. doi: 10.1213/00000539-197453060-00021

116. Kulesa PM, Bailey CM, Cooper C, Fraser SE. In ovo live imaging of avian embryos. Cold Spring Harb Protoc. (2010) 2010:pdb prot5446. doi: 10.1101/pdb.prot5446

117. Canaria CA, Lansford R. Advanced optical imaging in living embryos. Cell Mol Life Sci. (2010) 67:3489-97. doi: 10.1007/s00018-010-0440-5

118. Jefferies B, Tong Z, Nawroth R. Bioluminescence imaging in the chick chorioallantoic membrane assay. Methods Mol Biol. (2020) 2081:2117. doi: 10.1007/978-1-4939-9940-8_15

119. Jefferies B, Lenze F, Sathe A, Truong N, Anton M, von Eisenhart-Rothe $\mathrm{R}$, et al. Non-invasive imaging of engineered human tumors in the living chicken embryo. Sci Rep. (2017) 7:4991. doi: 10.1038/s41598-017-04572-1

120. Raghunathan R, Singh M, Dickinson ME, Larin KV. Optical coherence tomography for embryonic imaging: a review. J Biomed Opt. (2016) 21:50902. doi: 10.1117/1.JBO.21.5.050902

121. Teddy JM, Lansford R, Kulesa P. Four-color M, 4-D time-lapse confocal imaging of chick embryos. Biotechniques. (2005) 39:70310. doi: $10.2144 / 000112017$

122. McQuinn TC, Bratoeva M, Dealmeida A, Remond M, Thompson RP, Sedmera D. High-frequency ultrasonographic imaging of avian cardiovascular development. Dev Dyn. (2007) 236:350313. doi: 10.1002/dvdy.21357

123. Sharma A, Ishak N, Swee-Hin T, Pramanik M. High resolution, label-free photoacoustic imaging of live chicken embryo developing in bioengineered eggshell. J Biophotonics. (2020) 13:e201960108. doi: 10.1002/jbio.201960108

Conflict of Interest: The authors declare that the research was conducted in the absence of any commercial or financial relationships that could be construed as a potential conflict of interest.

Copyright (c) 2020 Winter, Koch, Löffler, Jelezko, Lindén, Li, Abaei, Zuo, Beer and Rasche. This is an open-access article distributed under the terms of the Creative Commons Attribution License (CC BY). The use, distribution or reproduction in other forums is permitted, provided the original author(s) and the copyright owner(s) are credited and that the original publication in this journal is cited, in accordance with accepted academic practice. No use, distribution or reproduction is permitted which does not comply with these terms. 